\title{
Sardine roe as a source of lipids to produce liposomes
}

Marta Guedes, Ana Rita Costa-Pinto, Virgínia Gonçalves, Joana MoreiraSilva, Maria Tiritan, Rui L. Reis, Helena Ferreira, and Nuno M. Neves

ACS Biomater. Sci. Eng., Just Accepted Manuscript • DOI: 10.1021/ acsbiomaterials.9b01462 Publication Date (Web): 07 Jan 2020

Downloaded from pubs.acs.org on January 10, 2020

\section{Just Accepted}

"Just Accepted" manuscripts have been peer-reviewed and accepted for publication. They are posted online prior to technical editing, formatting for publication and author proofing. The American Chemical Society provides "Just Accepted" as a service to the research community to expedite the dissemination of scientific material as soon as possible after acceptance. "Just Accepted" manuscripts appear in full in PDF format accompanied by an HTML abstract. "Just Accepted" manuscripts have been fully peer reviewed, but should not be considered the official version of record. They are citable by the Digital Object Identifier (DOI®). "Just Accepted" is an optional service offered to authors. Therefore, the "Just Accepted" Web site may not include all articles that will be published in the journal. After a manuscript is technically edited and formatted, it will be removed from the "Just Accepted" Web site and published as an ASAP article. Note that technical editing may introduce minor changes to the manuscript text and/or graphics which could affect content, and all legal disclaimers and ethical guidelines that apply to the journal pertain. ACS cannot be held responsible for errors or consequences arising from the use of information contained in these "Just Accepted" manuscripts. 


\section{Sardine roe as a source of lipids to produce liposomes}

Marta Guedes ${ }^{1,2}$, Ana R. Costa-Pinto ${ }^{3}$, Virgínia M. F. Gonçalves, Joana Moreira-Silva

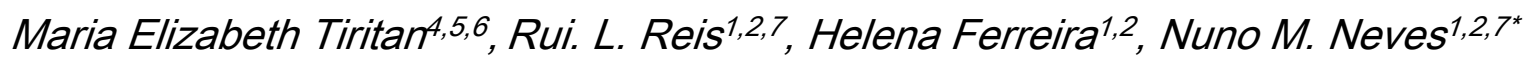

13B's Research Group, I3Bs - Research Institute on Biomaterials, Biodegradables and Biomimetics, University of Minho, Headquarters of the European Institute of Excellence on Tissue Engineering and Regenerative Medicine, AvePark, Parque de Ciência e Tecnologia, Zona Industrial da Gandra, 4805-017 Barco, Guimarães, Portugal 2ICVS/3B's - PT Government Associate Laboratory, Braga/Guimarães, 4805-017, Portugal ${ }^{3}$ Universidade Católica Portuguesa, CBQF - Centro de Biotecnologia e Química Fina Laboratório Associado, Escola Superior de Biotecnologia, Rua Arquiteto Lobão Vital 172, 4200-374 Porto, Portugal

${ }^{4}$ CESPU, Instituto de Investigação e Formação Avançada em Ciências e Tecnologias da Saúde, Rua Central de Gandra, 1317, 4585-116 Gandra PRD, Portugal 
IInterdisciplinary Centre of Marine and Environmental Research (CIIMAR), University of

Porto, Terminal de Cruzeiros do Porto de Leixões, Avenida General Norton de Matos, S/N,

4450-208 Matosinhos, Portugal

'Laboratório de Química Orgânica e Farmacêutica, Departamento de Ciências Químicas,

Faculdade de Farmácia da Universidade do Porto, Rua Jorge de Viterbo Ferreira 228, 4050-

313 Porto, Portugal

${ }^{7}$ The Discoveries Centre for Regenerative and Precision Medicine, Headquarters at University of Minho, Avepark 4805-017 Barco, Guimarães, Portugal

*Corresponding author: nuno@i3bs.uminho.pt

\begin{abstract}
Sea-derived materials have promising applications in the medical, pharmaceutical and biotechnological fields. Fish roe, e.g., is a highly nutritional product, presenting diverse beneficial effects for human health. Therefore, this work explored extracts of sardine (Sardina pilchardus) roe, due to the well-known health benefits of this fish, to produce novel and promising delivery systems. After morphological, histological and histochemical characterization of sardine roe, their lipids were extracted using two different approaches, namely Bligh and Dyer (BD) and methyl-tert-butyl ether (MTBE) methods. Gas chromatography/mass spectrometry analyses demonstrated that lipid extracts contain several fatty acids, such as $\omega 3$ polyunsaturated fatty acids. The lipids, specially phospholipids, were used to produce multilamellar liposomes (MLVs). These delivery systems presented size heterogeneity, a negative surface charge and ability to control the release of the encapsulated anti-
\end{abstract}


inflammatory drug, namely celecoxib. Biological assays indicated that MLVs produced with MTBE lipidic extracts presented a better cytocompatibility than those obtained by the BD method. This can be further improved if the lipid extracts are processed by chemical extraction. Therefore, sardine roederived lipids can produce drug delivery systems with the potential to be applied in the biomedical field.

\section{Keywords}

Sardine roe; Bligh and Dyer; methyl-tert-butyl ether; fatty acids; liposomes; cytocompatibility 


\section{Introduction}

Sea is still a largely unexploited resource of novel and promising biomaterials for biotechnological, pharmaceutical and medical applications. In addition to their large biodiversity, marine biomaterials are frequently biodegradable and biocompatible. An example of them is the squid viscera lecithin, which is usefully used in the food and pharmaceutical industries, due to its high amounts in polyunsaturated fatty acids as well as high oxidative stability. ${ }^{1}$ Salmon lecithin nanoliposomes were also used to encapsulate TGF$\beta 1$ (a protein with a crucial role in cell signaling), demonstrating the potential to be used in regenerative medicine. ${ }^{2}$ Other successful and well-recognized examples of marine biomaterials with biomedical applications are chitosan, collagen, and fucoidan. ${ }^{3-5}$

A promising raw marine material is fish roe that is the fish eggs included in the original ovarian sac. It is a highly nutritional valued product and it is expanding in international and national markets. ${ }^{6}$ Despite fish roe was considered in the past a by-product of the fish transformation industry, nowadays it is considered an important nutritional product. Caviar is the best-known form of fish roe products. ${ }^{6}$ Fish roe is rich in proteins containing essential amino acids, longchain $\omega 3$ polyunsaturated fatty acids (PUFA), mainly docosahexaenoic acid (DHA; C22:6w3) and eicosapentaenoic acid (EPA; C20:5 33 ), phosphatidylcholine, cholesterol, antioxidants 
(e.g. carotenoids and tocopherols) and minerals (e.g. iodine). ${ }^{7-9}$ The fish roe lipids have several potentialities, for instance, a growth inhibitory effect on colon cancer cells ${ }^{10}$ and an improvement in the liver function of patients with chronic liver diseases. ${ }^{11}$ Moreover, fish roe possesses antioxidant and immunostimulating properties. ${ }^{12}$ Fish roe fatty acids are also useful in the prevention of cardiovascular diseases ${ }^{13}$, in the improvement of visual function and learning ability, ${ }^{8}$ as cancer chemopreventive agents and in the treatment of mental disorders, type 2 diabetes, as well as inflammatory and autoimmune diseases. ${ }^{14}$ Additionally, fish roe lipids have been extensively used in the cosmetic field. For example, caviar extracts are in the cosmetic market since $1987 .{ }^{15}$ Consequently, fish roe derived-nutrients can be beneficial in functional and health foods, as well as in nutraceuticals and pharmaceutical formulations for various therapeutic applications.

In this work, sardine roe was used as a source of marine lipids. Sardine (Sardina pilchardus) is a multiple spawning fish, and eggs are released in batches over a period that starts in October and lasts until April. Each spawning batch presents oocytes in different developmental stages, and females can release around 400,000 eggs per year. ${ }^{16-17}$ Histochemical analysis of developmental oocytes was performed in this work to evaluate the distribution of the compounds of interest, such as lipids. Indeed, despite sardine being an 
excellent source of proteins, vitamins, minerals, and choline, this specie is one of the highest sources of $\omega 3$ PUFA. ${ }^{18-19}$ w3 PUFA are well-known for their effects in disease prevention, during all stages of human development. ${ }^{14}$ In fact, they are crucial to maintain the cell membrane composition and normal cell functions. ${ }^{20}$

Considering the above-mentioned features of sardine, and specifically of fish roe, this marine resource may be further exploited envisioning biomedical applications. For that, sardine roederived lipids, and in particular phospholipids, were used to produce liposomes. Indeed, due to their biological and technological advantages, liposomes are considered one of the most successful drug-carrier systems, existing numerous formulations currently in clinical practice. $^{21}$ There are several types of liposomes, being multilamellar (MLVs), large unilamellar (LUVs) and small unilamellar (SUVs) liposomes the most commonly used. MLVs consist of several concentric lipid bilayers, with a size range between 0.1 and $15 \mu \mathrm{m}$. LUVs and SUVs contain only a single bilayer membrane and a size ranging from 0.05 or 0.1 to 1 $\mu \mathrm{m}$, and from 25 to $50 \mathrm{~nm}$, respectively. ${ }^{22-23}$ SUVs are less stable than the other types of liposomes, due to the high curvature and consequent high surface tension and anomalies in the packaging of lipids. ${ }^{23-24}$ Additionally, LUVs have a higher volume fraction for encapsulation than SUVs for the same lipid concentration. ${ }^{23}$ Despite LUVs homogeneity and higher encapsulation efficiency of 
hydrophilic compounds, ${ }^{25} \mathrm{MLVs}$ have the advantage of incorporating considerable amounts of hydrophobic agents, since they contain larger lipid surfaces and number of membranes. ${ }^{26}$ This type of liposomes also provides a more gradual and sustained drug release than LUVs, because their membranes are progressively degraded at the site of action. ${ }^{27}$ Additionally, Lu et al. stated that marine phospholipid based-liposomes can have advantageous features, such as better oxidative stability, higher bioavailability, and superior fluidity when compared to other types of liposomes. ${ }^{25}$ Indeed, many of the physical properties of the liposomes, such as stability, permeability and phase transition temperature, are intrinsically related to the length and saturation degree of their phospholipids. To obtain sardine roe-derived lipids, two different approaches were used, namely Bligh and Dyer (BD) and methyl-tert-butyl ether (MTBE) methods. The BD method is widely used for the extraction of lipids from marine tissues, ${ }^{28}$ however, the use of chloroform is one of its major drawbacks. On the other hand, the MTBE method uses a nontoxic solvent ${ }^{29}$ and presents a recovery of lipids similar to the BD method. Therefore, this environmentally friendly method can be a good candidate to replace the "gold-standard" Folch or BD protocols. ${ }^{30}$ The fatty acids profile of the lipidic extracts was analyzed by gas chromatography/mass spectrometry (GC/MS) and the phospholipid and phosphatidylcholine contents were determined using the phosphorous 
(Barlett method) and the LabAssay ${ }^{\mathrm{TM}}$ Phospholipid assays, respectively. The characterization of the MLVs produced by the thin film hydration method included the analyses of their size distribution, surface charge, morphology, and thermal properties. Additionally, the cytotoxicity of the MLVs was evaluated using L929 cells, a mammalian mouse lung fibroblast cell line. These cells were selected since they are widely used for preliminary cytotoxicity evaluation for a wide range of biomaterials. ${ }^{31}$ The entrapment efficiency and release profile studies of celecoxib into MLVs were also performed. This drug is a specific inhibitor of cyclooxygenase-2 that exhibits analgesic and anti-inflammatory activities. ${ }^{32}$ Celecoxib is poorly soluble in water and presents serious cardiovascular side effects. Consequently, the developed liposomes can improve the solubility and the bioavailability of this non-steroidal anti-inflammatory drug (NSAID), and reduce its side effects, increasing its therapeutic index. To the best of our knowledge, the present work is the first reporting this characterization of sardine roe-derived lipids and liposomes. 


\section{Experimental Section}

\section{Materials}

Alcian Blue, ammonium molybdate, Dulbecco's modified Eagle's medium (DMEM), Fiske-

Subbarow reducer, HEPES hemisodium salt, Oil Red O, perchloric acid, phosphate buffer saline (PBS), osmium tetroxide, sodium carbonate, sodium sulfate, Supelco ${ }^{\circledR} 37$ Component FAME Mix, tert-butyl methyl ether, tricosanoic acid and celecoxib was obtained from abcr $\mathrm{GmbH}$, Karlsruhe, Germany. Acetonitrile HPLC grade and acetic acid were acquired from Fisher Chemical, Leicestershire, UK, and Panreac, Barcelona, Spain, respectively. AntibioticAntimycotic, fetal bovine serum (FBS) and quant-iT ${ }^{\mathrm{TM}}$ Pico Green ${ }^{\circledR}$ dsDNA Assay Kit were obtained from Life Technologies, Carlsbad, CA. CellTiter $96^{\circledR}$ AQueous One Solution Cell Proliferation Assay was purchased from Promega, Madison, USA. Chloroform and methanol were obtained from Fisher Chemical, Loughborough, Leicestershire. Dimethyl sulfoxide (DMSO) and eosin were purchased from AMRESCO, Solon, USA and Applied biosystems, Warrington, UK, respectively. Formalin, hematoxylin and micro BCA ${ }^{\mathrm{TM}}$ Protein Assay kit were obtained from Thermo Fisher Scientific, Kalamazoo, MI. Glutaraldehyde 25\% were obtained from Merck KGaA, Darmstadt, Germany. Acetone, ethanol, hexane and sulfuric acid were obtained from Carlo Erba Reagents, Val de Reuil, France. Hydrochloric acid and LabAssay ${ }^{\mathrm{TM}}$ 
Phospholipid were purchased from Honeywell, Seelze, German and Wako, Osaka, Japan, respectively. Masson's Trichome and paraffin were obtained from Bio-optica, Milano, Italy.

\section{Methods \\ Sample preparation}

Fresh sardine (Sardina pilchardus) roe, captured at the Portuguese mainland coast, were kindly donated by a local fisherman in March or October 2017. Samples for lipid extraction were then weighed and stored at $-20^{\circ} \mathrm{C}$.

\section{Scanning electron microscopy analyses}

Sardine roe samples were prepared for scanning electron microscopy (SEM) analyses, as described by Gwo et al. ${ }^{33}$ Briefly, fresh sardine roe was fixed with $2.5 \%$ glutaraldehyde in $0.01 \mathrm{M}$ PBS for $4 \mathrm{~h}$, at $4{ }^{\circ} \mathrm{C}$, and post fixed with $2 \%$ osmium tetroxide in the same buffer for $2 \mathrm{~h}$. Samples were then dehydrated using a series of increasing percentages of ethanol in water. Samples were submerged in acetone to dry before being sputter-coated with platinum (EM ACE600, Leica), and then they were analyzed by SEM (JSM-6010 LV, JEOL). 


\section{Histological and histochemical analyses}

For histological analyses, fresh sardine roe was fixed in $10 \%$ buffered formalin for 2 days.

After this period of time, samples were dehydrated using a series of increasing percentages of ethanol in water. Then, the dehydrated samples were embedded in paraffin and sectioned at $4 \mu \mathrm{m}$ thickness (HM 560, Microm). Sections were then deparaffinized, rehydrated through a series of decreasing percentages of ethanol in water, and stained with Hematoxylin-eosin (H\&E), Alcian Blue (AB) or Masson's Trichrome (MT) staining. H\&E staining was used for the study of the different stages of the sardine reproductive cycle (hematoxylin and eosin stain the acidic and basic components of the oocytes, respectively), $A B$ for acidic glycosaminoglycans (GAGs) that are sulfated $(\mathrm{pH} 2.5)$, and MT for collagen fibers. Sardine roe was also cryostatically sectioned at 8-10 $\mu \mathrm{m}$ thickness for lipid detection. Oil Red O staining was used to detect general and neutral lipids.

\section{Extraction of sardine roe derived-lipids}

\section{Bligh and Dyer Method}

Extraction following the Bligh and Dyer (BD) method was performed as originally described. ${ }^{28}$ Briefly, $100 \mathrm{~g}$ of a sample containing (or adjusted to contain) $80 \mathrm{~g}$ of water was homogenized 
with $100 \mathrm{~mL}$ chloroform and $200 \mathrm{~mL}$ methanol. The solution was then rehomogenized with $100 \mathrm{~mL}$ chloroform, and after that $100 \mathrm{~mL}$ water was added. The proportions of chloroform, methanol, and water before and after dilution were 1:2:0.8 and 2:2:1.8, respectively. After filtration (under vacuum), the final biphasic system was separated and the lower phase (chloroform) was collected. Then, the organic phase was dehydrated with sodium sulfate anhydrous and dried under vacuum or under a stream of nitrogen.

\section{Methyl-tert-butyl ether extraction}

Methyl-tert-butyl ether (MTBE) extraction was performed as described elsewhere. ${ }^{34}$ Briefly, $3 \mathrm{mg}$ freeze-dried sample was homogenized in an Ultra Turrax (T18 Basic, IKA) for 2 min with $120 \mu \mathrm{L}$ ice-cold $75 \%$ methanol. Then, $300 \mu \mathrm{L}$ MTBE was added and the mixture was shaken for $1 \mathrm{~h}$ at room temperature (RT). Phase separation was induced by adding $75 \mu \mathrm{L}$ water. Upon $10 \mathrm{~min}$ of incubation at RT, the sample was centrifuged at $12000 \mathrm{~g}$ for $15 \mathrm{~min}$, at $4{ }^{\circ} \mathrm{C}$.

Organic and aqueous phases were separately collected and then the organic (upper) phase was dehydrated with sodium sulfate anhydrous and dried under vacuum or under a stream of nitrogen. 


\section{Extraction of free fatty acids}

To remove the free fatty acids from the obtained lipidic extracts using the methods described above, chemical extraction was used. Firstly, the fatty acids were extracted with $0.02 \mathrm{~N}$ sodium carbonate and, after acidification of the aqueous phase with $37 \%$ hydrochloric acid, the free fatty acids were re-extracted with hexane. The free fatty acid organic solutions were then dehydrated and dried as previously referred.

\section{Fatty acids analysis}

The fatty acids profile of the extracts was analyzed by GC/MS, using a procedure adapted from Sertoglu et al. ${ }^{35}$ Briefly, the fatty acids were derivatized to their methyl esters (FAMEs). For that, $50 \mu \mathrm{L}$ of the sample or standard solutions, $1 \mathrm{~mL}$ methanolic sulfuric acid and $100 \mu \mathrm{L}$ internal standard solution (Tricosanoic acid, C23:0; $500 \mu \mathrm{g} / \mathrm{mL}$ ) were added to a digestive tube. The transmethylation occurred at $100^{\circ} \mathrm{C}$ for $2 \mathrm{~h}$. After cooling the tubes at $\mathrm{RT}, 2 \mathrm{~mL}$ hexane was added. The organic (upper) phase was collected and dehydrated with sodium sulfate anhydrous. $100 \mu \mathrm{L}$ of the sample was transferred to a GC injection vial. To perform the analyses, a Scion 436-GC chromatograph (Bruker Daltonics) equipped with a SLB-IL100 
capillary GC Column, $30 \mathrm{~m} \times 0.25 \mathrm{~mm} \times 0.20 \mu \mathrm{m}$ (Catalog no. 28884-U), was used. The sample injection was performed in a split mode at $240^{\circ} \mathrm{C}$ with a $20: 1$ split ratio. Helium was used as carrier gas. The temperature was initially programmed at $50{ }^{\circ} \mathrm{C}$ and held for 5 min, followed by an increase to $230^{\circ} \mathrm{C}$ at $3^{\circ} \mathrm{C} / \mathrm{min}$. The identification and quantification of the fatty acids were achieved using standard solutions at different concentrations $(50,100,200,350$ and $500 \mathrm{mg} / \mathrm{L})$, the Supelco ${ }^{\circledR} 37$ Component FAME Mix as well as the OpenChrom ${ }^{\circledR}$ software.

\section{Production and characterization of sardine roe derived-MLVs}

ML Vs preparation and phospholipid and phosphatidylcholine quantification

MLVs were prepared by the thin film hydration method. ${ }^{36}$ The dried lipid films obtained after organic solvents elimination were hydrated with HEPES buffer and mixed using a vortex to produce MLVs, keeping the temperature of the hydrating medium around $37^{\circ} \mathrm{C}$.

The phospholipid content was quantified by the Bartlett method ${ }^{37}$ and the concentration of the phospholipids containing choline as the polar group was measured using the LabAssay ${ }^{\mathrm{TM}}$ Phospholipid. The Bartlett method is based on the colorimetric determination of inorganic phosphate. Phospholipids are disrupted with perchloric acid, giving rise to quantifiable free inorganic phosphate. Next, the inorganic phosphate is converted to phosphomolybdic acid 
by ammonium molybdate, which is reduced to a blue colored complex by 4-amino-2-naphthyl-

4-sulphonic acid in boiling water. The absorbance was determined at $830 \mathrm{~nm}$ in a microplate reader (Synergy HT, BioTek).

With the LabAssay ${ }^{\mathrm{TM}}$ Phospholipid, phospholipids were hydrolyzed to choline by phospholipase D. Afterwards, the choline is oxidized by choline oxidase, producing hydrogen peroxide. The hydrogen peroxide leads to the quantitative oxidative condensation of $\mathrm{N}$-ethyl$\mathrm{N}$-(2-hydroxy-3-sulfopropyl)-3,5-dimethoxyaniline sodium salt and 4-aminoantipyrine, in the presence of peroxidase, producing a blue pigment. The concentration of phosphatidylcholine in the sample was determined by measuring the absorbance at $600 \mathrm{~nm}$ in the microplate reader referred before.

Size distribution, zeta potential and morphology of $M L V S$

The size, polydispersity index (PDI) and zeta potential of the MLVs in a concentration of $\approx$ $500 \mu \mathrm{M}$ were determined at $\mathrm{pH} 7.4$ (HEPES buffer) and at $37^{\circ} \mathrm{C}$ by dynamic light scattering (DLS) and laser Doppler micro-electrophoresis, respectively, using a zetasizer (Nano ZS, Malvern Instruments Ltd). Liposomes morphology was evaluated using a high-resolution field emission scanning electron microscope (FE-SEM; Auriga Compact, Zeiss). Prior to analyses, 
the MLVs concentration was adjusted to $25 \mu \mathrm{M}$ in the presence of $2 \%$ ethanol and placed into the surface of a support film of carbon (type-B 400 mesh $\mathrm{Cu}$ ).

\section{Differential scanning calorimetry}

The thermal properties of the freeze-dried MLVs were determined using a differential scanning calorimeter (DSC Q100, TA instruments). Nitrogen gas with a flow rate of $50 \mathrm{~mL} / \mathrm{min}$ was purged through the DSC aluminum pan, which contained around $5 \mathrm{mg}$ of lyophilized sample. The analyses were performed with a temperature range from - 35 to 100 ${ }^{\circ} \mathrm{C}$, at $5^{\circ} \mathrm{C} / \mathrm{min}$. Cooling was achieved with a refrigerated cooling system.

\section{Biological assays}

Cell culture

L929 cell line was used to evaluate the cytotoxicity of the liposomes. Cells were cultured in DMEM, supplemented with $10 \%$ heat-inactivated FBS and $1 \%$ antibiotic/antimycotic solution (100 U/mL penicillin and $100 \mathrm{mg} / \mathrm{mL}$ streptomycin). Cells were incubated at $37^{\circ} \mathrm{C}$ in $5 \% \mathrm{CO}_{2}$ - 95\% air conditions. The culture medium was changed every $2 / 3$ days and the culture was split every 7 days. For the determination of the metabolic activity, cell proliferation and total 
protein content, cells were seeded on 24-well plates at a density of $1 \times 10^{5}$ cells. After $24 \mathrm{~h}$ in culture, cells were incubated with liposomes at different concentrations in culture medium: $0,0.25,0.50,1.00,1.50$ and $2.00 \mathrm{mM}$. Cells incubated with $10 \%$ DMSO in culture medium were used as the positive control for cell death. Cells were retrieved after 24, 48 and $72 \mathrm{~h}$. Three independent experiments were performed.

\section{Determination of metabolic activity}

L929 metabolic activity was evaluated using the colorimetric method CellTiter $96^{\circledR}$ AQueous One Solution Cell Proliferation Assay, according to the manufacturer's instructions. This assay is based on the bioreduction of a tetrazolium compound, 3-(4,5-dimethylthiazol-2-yl)5-(3-carboxymethoxyphenyl)-2-(4-sulphofenyl)-2H-tetrazolium (MTS), into a water-soluble brown formazan product in metabolically active cells. The absorbance measured at $490 \mathrm{~nm}$ (Synergy HT, BioTek) is directly proportional to the number of viable cells in culture.

\section{Determination of cell proliferation}

Cell proliferation was determined using the Quant-iT ${ }^{\mathrm{TM}}$ Pico Green ${ }^{\circledR}$ dsDNA Assay Kit, according to the manufacturer's instructions. The fluorescence intensity was measured at 
excitation and emission wavelengths of $485 \pm 20 \mathrm{~nm}$ and $528 \pm 20 \mathrm{~nm}$, respectively, in a microplate reader (Synergy HT, BioTek). The DNA concentration for each sample was quantified using a standard curve of DNA concentration (range of $0-2 \mu \mathrm{g} / \mathrm{mL}$ ) versus fluorescence intensity.

\section{Quantification of total protein}

Total protein content was quantified using the Micro BCA ${ }^{\mathrm{TM}}$ Protein Assay kit, according to the manufacturer's instructions. This colorimetric method uses bicinchoninic acid (BCA) as the detection reagent for $\mathrm{Cu}^{+}$, which is formed when $\mathrm{Cu}^{2+}$ is reduced by proteins in an alkaline environment. Two molecules of $\mathrm{BCA}$ chelate one $\mathrm{Cu}^{+}$with the production of a purple-colored product. This water-soluble complex exhibits a strong absorbance at $562 \mathrm{~nm}$ that is linear to protein concentration. This parameter was calculated using a standard curve of albumin concentration (range of $0-40 \mu \mathrm{g} / \mathrm{mL}$ ) versus absorbance.

\section{Celecoxib entrapment efficiency}

Celecoxib loaded-MLVs prepared from unprocessed samples obtained by MTBE method were produced using the thin film hydration method mentioned above. The sardine roe extract 
was mixed with $1 \mathrm{mg}$ celecoxib, and the MTBE was removed under vacuum or under a stream of nitrogen. Non-incorporated celecoxib was separated using Vivaspin ${ }^{\circledR}$ ultrafiltration units, by two subsequent centrifugation cycles of $2 \mathrm{~h}$, at $5000 \mathrm{rpm}$ and $5^{\circ} \mathrm{C}$.

The concentration of celecoxib encapsulated into MLVs was determined by a HPLC system (Merck Hitachi), equipped with a quaternary pump (L-7100), an interface (D-7000), a diode array detector (L-7455), and an auto-sampler (L-7200). The procedure was adapted from

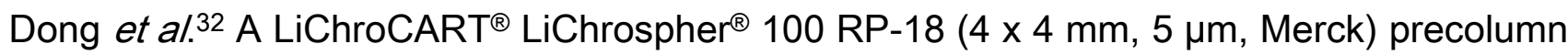
and a LiChroCART ${ }^{\circledR}$ LiChrospher ${ }^{\circledR} 100$ RP-18 $(250 \times 4.6$ mm, $5 \mu \mathrm{m}$, Merck) column were used. The analyses were performed at RT, in an isocratic mode, using acetonitrile and $0.1 \%$ $(\mathrm{v} / \mathrm{v})$ acetic acid (65:35) as mobile phase, at a flow rate of $1 \mathrm{~mL} / \mathrm{min}$. The injection volume was $10 \mu \mathrm{L}$ and the monitorization of the NSAID was carried out at $250 \mathrm{~nm}$. The content of celecoxib in the MLVs was quantified using a standard curve of celecoxib concentration (range from 2 to $131 \mu \mathrm{M}$ ) versus the peak area of the chromatograms. Standards and samples were diluted with methanol.

The drug entrapment efficiency was calculated using the equation 1 . Since there is lipid and drug loss during the MLVs production (e.g. celecoxib precipitation, due to its low solubility in 
aqueous solutions), it was considered the concentration of celecoxib that is effectively present in the liposomes suspension to determine the entrapment efficiency.

$$
\text { Entrapment efficiency }(\%)=\frac{\text { Concentration of celecoxib encapsulated into MLVs }}{\text { Initial concentration of celecoxib in the MLVs suspension }} \times 100
$$

\section{$\underline{\text { In vitro drug release profile }}$}

The release of celecoxib from MLVs was determined using dialysis devices (3.5-5 kD of molecular weight cut off). The dialysis was performed against HEPES buffer (release medium), with constant stirring at $150 \mathrm{rpm}$ and $37^{\circ} \mathrm{C}$. At $1,2,3,4,5,6$ and 7 days, $20 \mu \mathrm{L}$ of MLVs was withdrawn to measure the celecoxib content. At the same time-points, the release medium was also collected and replaced with an equal volume of HEPES buffer. The collected samples were analyzed by HPLC, as previously described.

\section{Statistical analysis}

Statistical analyses were performed using GraphPad Prism software v5.01 (GraphPad Software, Inc., USA). To test the assumption of Normality, the Kolmogorov-Smirnov test was applied. As the data obtained in the assays used to determine the yields of the extraction 
methods followed a normal distribution, the statistical significance of the difference between the two groups was evaluated by the t-test. -In biological assays, data did not follow a normal distribution, being the non-parametric Kruskal-Wallis and Dunn's multiple comparison tests applied to evaluate the statistical significance of the difference between the conditions assessed. Differences were considered statistically significant when $p<0.05$. 


\section{Results \\ Assessment of sardine roe morphology, histology, and histochemistry}

Figure 1 shows the surface morphology of the sardine roe analyzed by SEM. Oocytes with different sizes $(8-350 \mu \mathrm{m})$ are visualized, being the size related to the different stages of their development. Indeed, in the spawning capable phase of the reproductive cycle of sardine, oocytes are in different developmental stages. ${ }^{38}$ Primary to secondary growth oocytes as well as oocyte maturation can be observed in the histological sections presented in Figure 2A. Primary growth oocytes (PG) have a large and centrally located nucleus surrounded by a cytoplasm densely stained with hematoxylin (the cytoplasm is basophilic at this stage). Cortical alveolar (CA) oocytes have unstained empty vacuoles (named yolk vesicles) in the cytoplasm, which then migrate to the periphery of the cytoplasm forming first a single layer and then several peripheral rows (cortical alveoli). Primary vitellogenic (Vtg1) oocytes have small yolk vesicles within their periphery (the yolk vesicles extend $3 / 4$ of the distance from the periphery to the perinuclear zone) and oil droplets also appear in the ooplasm at this stage; secondary vitellogenic (Vtg2) oocytes present more and larger yolk vesicles and oil droplets throughout the cytoplasm; tertiary vitellogenic (Vtg3) oocytes have 
numerous large yolk vesicles and the oil droplets surround the nucleus; in mature oocytes, the nucleus is dissolved and the ooplasm consists of yolk bodies. ${ }^{39}$

Strong AB positivity, which indicates the presence of sulfated GAGs, was observed in oocytes mainly at the beginning of the development (PG, CA, Vtg1 and Vtg2 oocytes; Figure 2B). In $\operatorname{Vtg} 3$ and mature oocytes, the staining is stronger at the periphery of the oocytes. A strong stain was also obtained in the extracellular space.

With the MT staining (collagen fibers staining), oocytes of sardine appear unstained (Figure 2C).

The presence of neutral lipids was indicated with Oil Red O staining of unfixed fresh samples, processed directly in a cryostat. In Figure 2D, it is also possible to observe that the oil deposits increase both in size and number throughout development, in both oil droplets and yolk vesicles. 

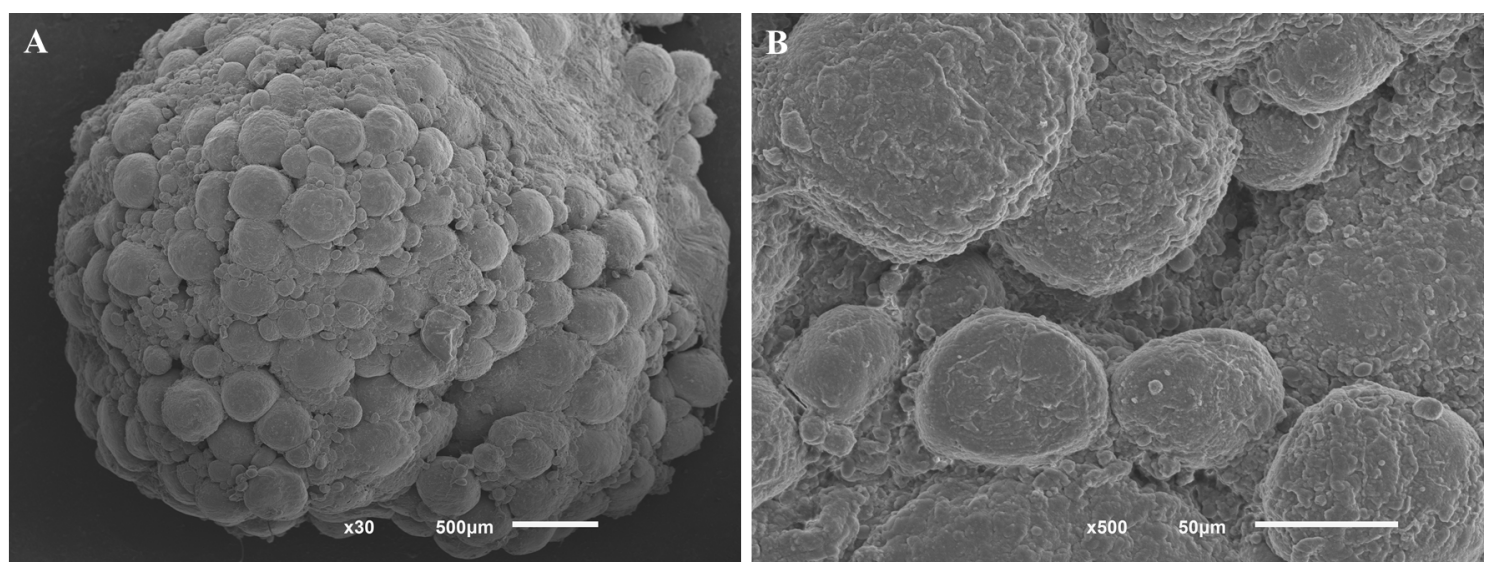

Figure 1 - SEM micrographs of sardine roe, showing oocytes at different stages of development: A: 30x. B: 500x. 

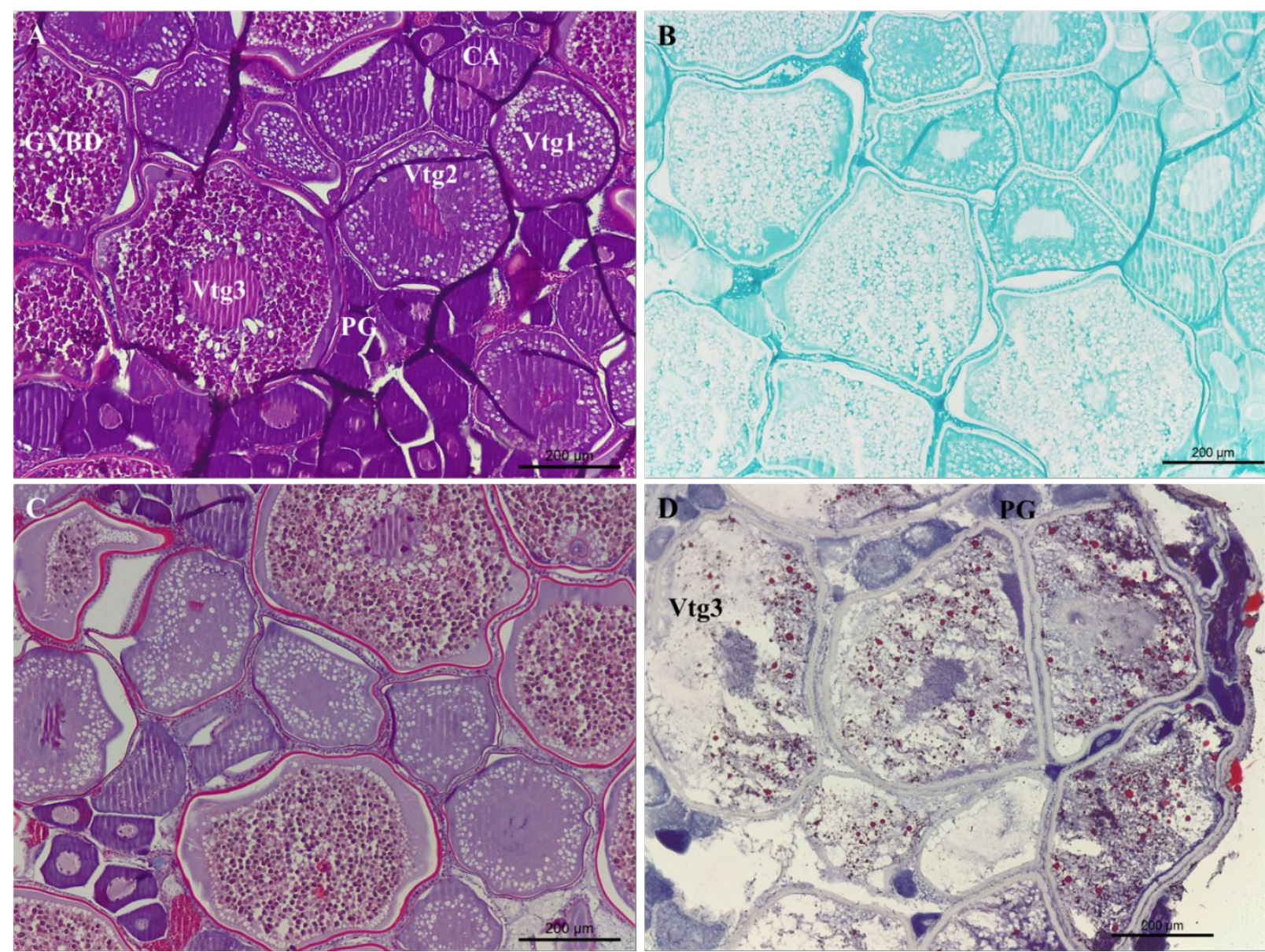

Figure 2 - Histological sardine roe sections, showing oocytes at different stages of development, using different stains: A: Hematoxylin-eosin. B: Alcian Blue. C: Masson's Trichrome. D: Oil Red O and Hematoxylin. CA: cortical alveolar oocytes; GVBD: germinal vesicle breakdown oocytes; PG: primary growth oocytes; Vtg1: primary vitellogenic oocytes; Vtg2: secondary vitellogenic oocytes; Vtg3: tertiary vitellogenic oocytes. Scale bar $=200 \mu \mathrm{m}$.

\section{Characterization of lipid extracts}

\section{Fatty acids profile}


In order to obtain a more cytocompatible lipid fraction, the separation of free fatty acids by chemical extraction was performed. Consequently, two samples were evaluated, namely unprocessed and processed samples. The fatty acids composition of the lipid extracts derived from the unprocessed and processed samples, obtained by both methods, is presented in Table 1. About nineteen fatty acids were quantitatively detected in all samples. The predominant fatty acids were $\mathrm{C} 16: 0, \mathrm{C} 18: 1 \Delta 9$ trans, $\mathrm{C} 22: 6 \omega 3, \mathrm{C} 18: 0, \mathrm{C} 16: 1 \omega 7, \mathrm{C} 14: 0$ and C20:5 $\omega 3$. Table 1 shows that saturated fatty acids (SFA) constituted nearly half of the total fatty acids in lipids extracted from sardine roe. The abundance of C16:0 accounted for about $40 \%$ in all samples. Monounsaturated fatty acids (MUFA) and PUFA accounted for about $27 \%$ and $14 \%$ of total fatty acids, respectively. $C 18: 1 \Delta 9$ trans, $C 16: 1 \omega 7$ and $C 18: 1 \Delta 9$ cis were the most common MUFA. DHA (C22:6w3) was found to be the major $\omega 3$ PUFA, and the third major fatty acid in all samples. The proportions of $\omega 6$ PUFA were relatively low in all samples $(<1 \%$ of total fatty acids). Although the percentage of fatty acids is similar in both extraction methods, a higher heterogeneity in fatty acids profile was obtained with the BD method (Table 1). For example, $C 14: 1 \omega 5, C 17: 1 \omega 8$ and $C 22: 1 \omega 11$ (MUFA) and $C 18: 2 \omega 6, C 20: 2 \omega 6$ and C22:5w6 (PUFA) were not detected in MTBE-derived lipidic extracts. Chemical extraction seems to lead to some loss of fatty acids, such as C20:5 $\omega 3$ and $\omega 6$ PUFA. 
Table 1 - Fatty acids profile of the unprocessed and processed sardine roe extracts obtained with $\mathrm{BD}$ and MTBE methods. Data are shown in percentage.

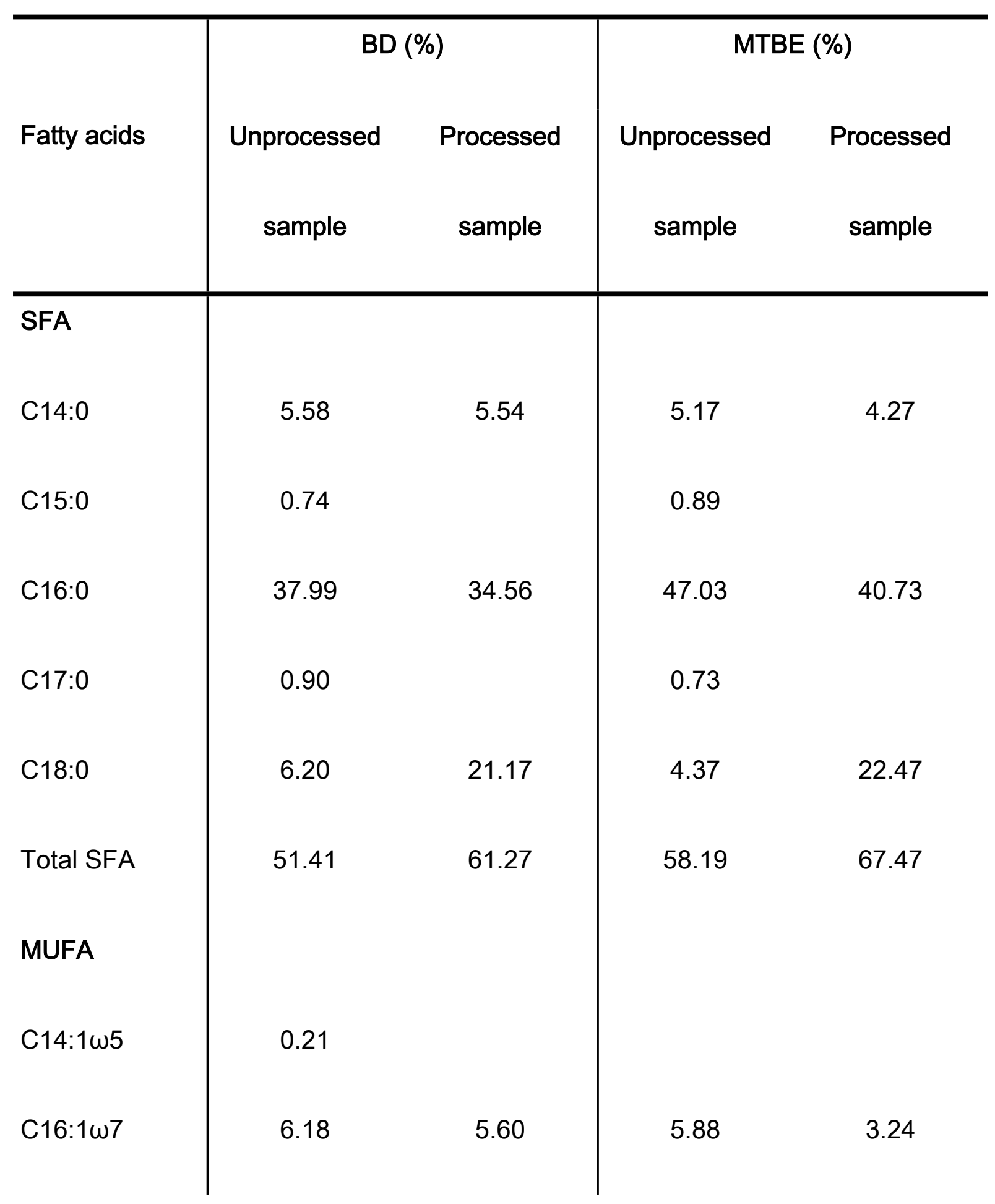




\begin{tabular}{|c|c|c|c|c|}
\hline C17:1w8 & 0.27 & & & \\
\hline $\mathrm{C} 18: 1 \Delta 9$ trans & 19.85 & 22.39 & 18.58 & 17.05 \\
\hline $\mathrm{C} 18: 1 \Delta 9 \mathrm{cis}$ & 3.31 & & 1.93 & 2.60 \\
\hline 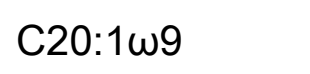 & 0.37 & & 0.23 & \\
\hline $\mathrm{C} 22: 1 \omega 11$ & 0.13 & & & \\
\hline Total MUFA & 30.32 & 27.99 & 26.62 & 22.89 \\
\hline PUFA, $\omega 3$ & & & & \\
\hline$C 20: 5 \omega 3$ & 4.24 & & 4.52 & \\
\hline$C 22: 5 \omega 3$ & 0.30 & & & \\
\hline C22:6w3 & 12.91 & 8.39 & 10.39 & 5.49 \\
\hline Total w3 PUFA & 17.45 & 8.39 & 14.91 & 5.49 \\
\hline PUFA, $\omega 6$ & & & & \\
\hline$C 18: 2 \omega 6$ & 0.28 & & & 4.16 \\
\hline$C 20: 2 \omega 6$ & 0.09 & & & \\
\hline C20:4w6 & 0.33 & & 0.29 & \\
\hline C22:5w6 & 0.13 & 2.35 & & \\
\hline
\end{tabular}




\section{Characterization of MLVs}

Yield of the extraction methods and resulting phospholipid and phosphatidylcholine concentrations

The efficiency in lipid extraction of each method in terms of yield and phospholipid and phosphatidylcholine concentrations is presented in Table 2. The MTBE method led to a significative higher percentage of extracted lipids: $\approx 12$ and $16 \%$ for BD and MTBE, respectively, in terms of weight of the freeze-dried samples. Table 2 also shows that, despite the higher yield of MTBE, the different solvents used do not significantly influence the phospholipids and phosphatidylcholine concentrations.

Table 2 - Yield of the BD and MTBE methods, and concentration of phospholipid (PL) and phosphatidylcholine $(P C)$ in the extracts. Data are shown as arithmetic means \pm SD.

\begin{tabular}{l|l|l|l}
\hline Extraction & Yield (g/g) & {$[\mathrm{PL}](\mathrm{mmol} / \mathrm{g})$} & {$[\mathrm{PC}](\mathrm{mmol} / \mathrm{g})$} \\
method & & & \\
\hline
\end{tabular}




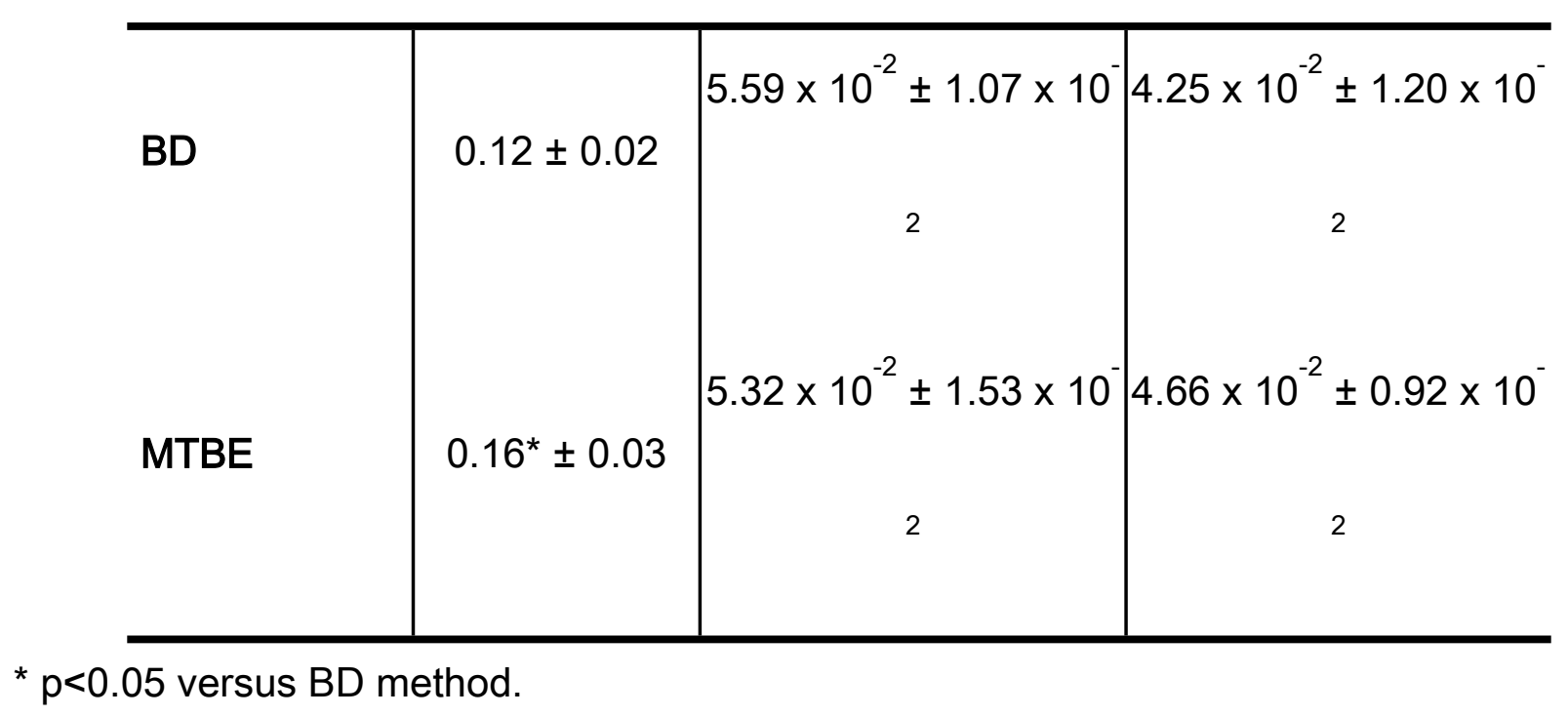

MLVs size distribution, zeta potential and morphology

In Table 3 is possible to confer the size, PDI and zeta potential of the produced MLVs using lipids obtained by the two extraction methods, submitted or not to chemical extraction. MLVs population is heterogeneous, which is in agreement with the respective PDI values (PDI > 0.2). The zeta potential values indicate that MLVs have a significant negative surface charge (Table 3). 
Table 3 - Diameter, PDI and zeta potential of MLVs produced with different extracts, obtained using BD and MTBE methods, submitted or not to chemical extraction. Data are shown as arithmetic means \pm SD.

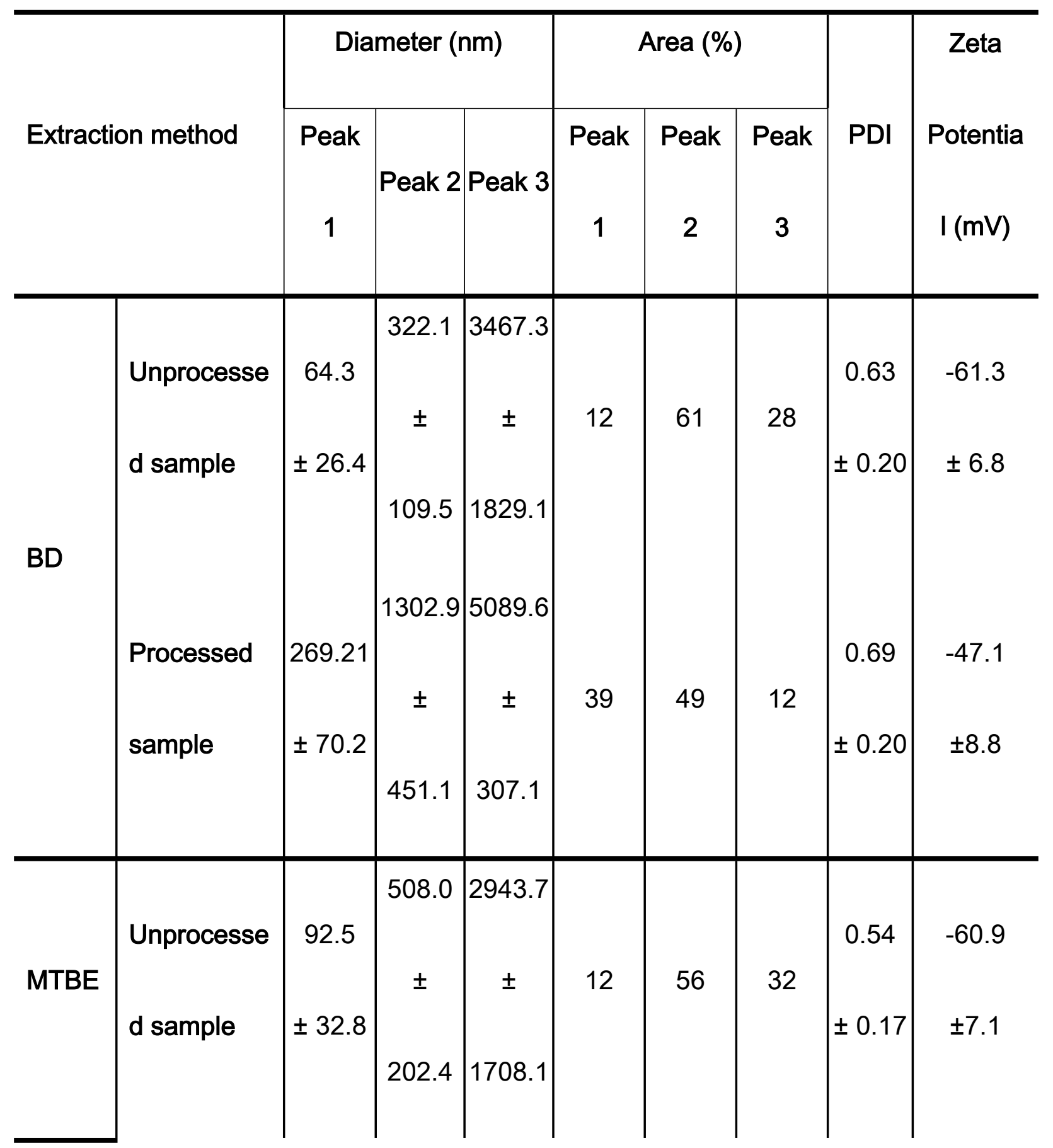




\begin{tabular}{l|l|l|l|l|l|l|l|l|l}
\hline Processed & 31.8 & 161.9 & 1475.4 & & & & 0.55 & -59.7 \\
sample & \pm 12.4 & \pm 83.3 & \pm 51.6 & & & & & \\
\end{tabular}

In Figure 3 is possible to analyze the size distribution of the MLVs, which corroborates the DLS data, as well as their spherical shape.
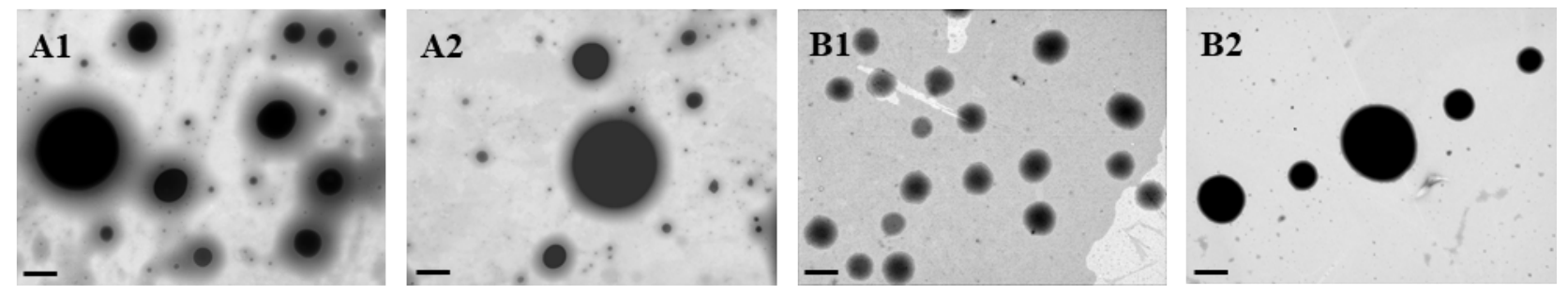

Figure 3 - FE-SEM micrographs of the MLVs produced with different extracts obtained by BD (A) or MTBE (B) methods and submitted (1) or not (2) to chemical extraction. Scale bar $=1 \mu \mathrm{m}$.

\section{Phase transition temperature}

The thermal properties of MLVs were characterized by DSC. The data showed three endothermic peaks for MLVs produced by both extraction methods, and their respective unprocessed and processed samples.

For BD method, the DSC curves of unprocessed sample-derived liposomes presented the first endothermic peak at $-6.83 \pm 1.44{ }^{\circ} \mathrm{C}$, between -22.95 and $1.51^{\circ} \mathrm{C}$, the second at 15.00 $\pm 1.58^{\circ} \mathrm{C}$, between $5.72-23.43^{\circ} \mathrm{C}$, and the third at $30.42 \pm 0.80^{\circ} \mathrm{C}$, between $26.68-33.93$ 
${ }^{\circ} \mathrm{C}$. Regarding the processed sample-derived liposomes, the first peak appeared at $-10.42 \pm$ $4.90{ }^{\circ} \mathrm{C}$, temperature range from -20.04 to $-1.18{ }^{\circ} \mathrm{C}$, the second at $11.46 \pm 0.96{ }^{\circ} \mathrm{C}$, temperature range from $0.49-23.31^{\circ} \mathrm{C}$, and the third at $30.90 \pm 0.44{ }^{\circ} \mathrm{C}$, temperature range from $25.85-35.50^{\circ} \mathrm{C}$. A representative DSC curve is presented in Figure 4.

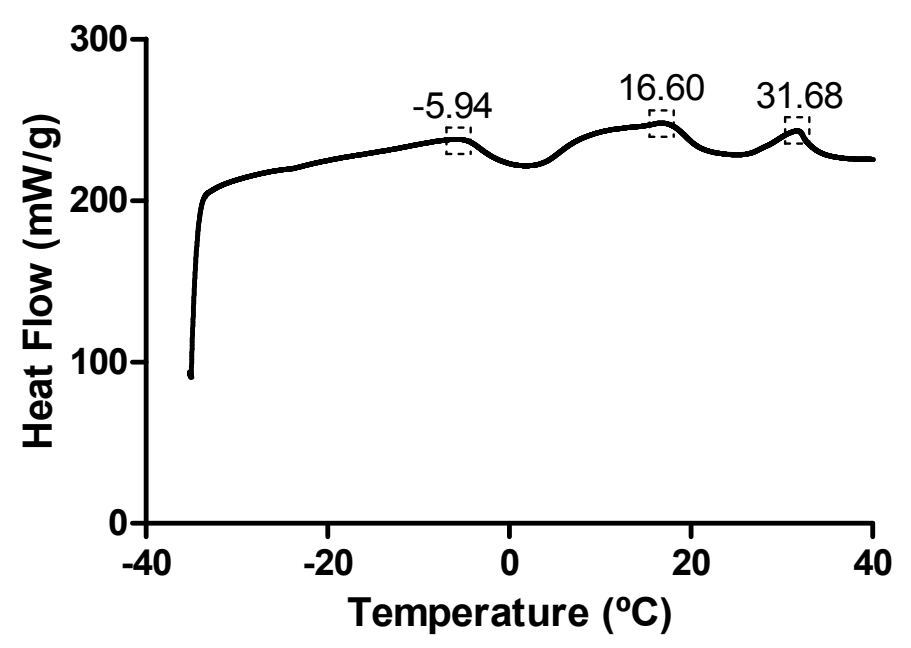

Figure 4-DSC curve of MLVs prepared from the unprocessed sample obtained by the BD method.

For MTBE method, the DSC curves of unprocessed sample-derived liposomes showed the first peak at $-13.75 \pm 6.50^{\circ} \mathrm{C}$, between -18.01 and $-0.83^{\circ} \mathrm{C}$, the second at $18.82 \pm 0.61^{\circ} \mathrm{C}$, $7.43-23.46{ }^{\circ} \mathrm{C}$, and the third at $27.56 \pm 0.35^{\circ} \mathrm{C}, 23.91-34.56^{\circ} \mathrm{C}$. In relation to processed sample-derived liposomes, three endothermic peaks were also detected: the first peak 
around $-6.48{ }^{\circ} \mathrm{C}$, temperature range from -8.96 to $16.00{ }^{\circ} \mathrm{C}$, the second around $21.21^{\circ} \mathrm{C}$, $17.98-24.58^{\circ} \mathrm{C}$, and the third around $35.76^{\circ} \mathrm{C}, 31.12-42.48^{\circ} \mathrm{C}$.

\section{Biological activity}

Metabolic activity and cell proliferation determination

Standard cell biology protocols were used to assess the effect of MLVs on cell metabolic activity and proliferation. Regarding metabolic activity, MLVs prepared from unprocessed samples obtained by the BD method presented toxicity for L929 cells at the highest tested concentrations $(1.00,1.50$ and $2.00 \mathrm{mM})$ at all time-points $(24,48$ and $72 \mathrm{~h}$; Figure $5 \mathrm{~A})$. The cytotoxic effect on L929 metabolic activity was reduced when the fraction of the fatty acids was removed by chemical extraction. However, the difference was statistically significant only for 0.25 and $0.50 \mathrm{mM}$ concentrations at $24 \mathrm{~h}$. The negative effect over the metabolic activity of the cells was reduced using MLVs prepared with lipidic extracts obtained by the MTBE method (Figure 5B). The differences between the effect of the unprocessed and processed samples-derived liposomes were statistically significant only for concentrations 0.50 (72 h), $1.00(24 \mathrm{~h})$ and $2.00 \mathrm{mM}(48 \mathrm{~h})$. 
A

Bligh and Dyer

Time (h)

$\square 24 \mathrm{~h}$

$\square 48 \mathrm{~h}$

$\square 72 \mathrm{~h}$

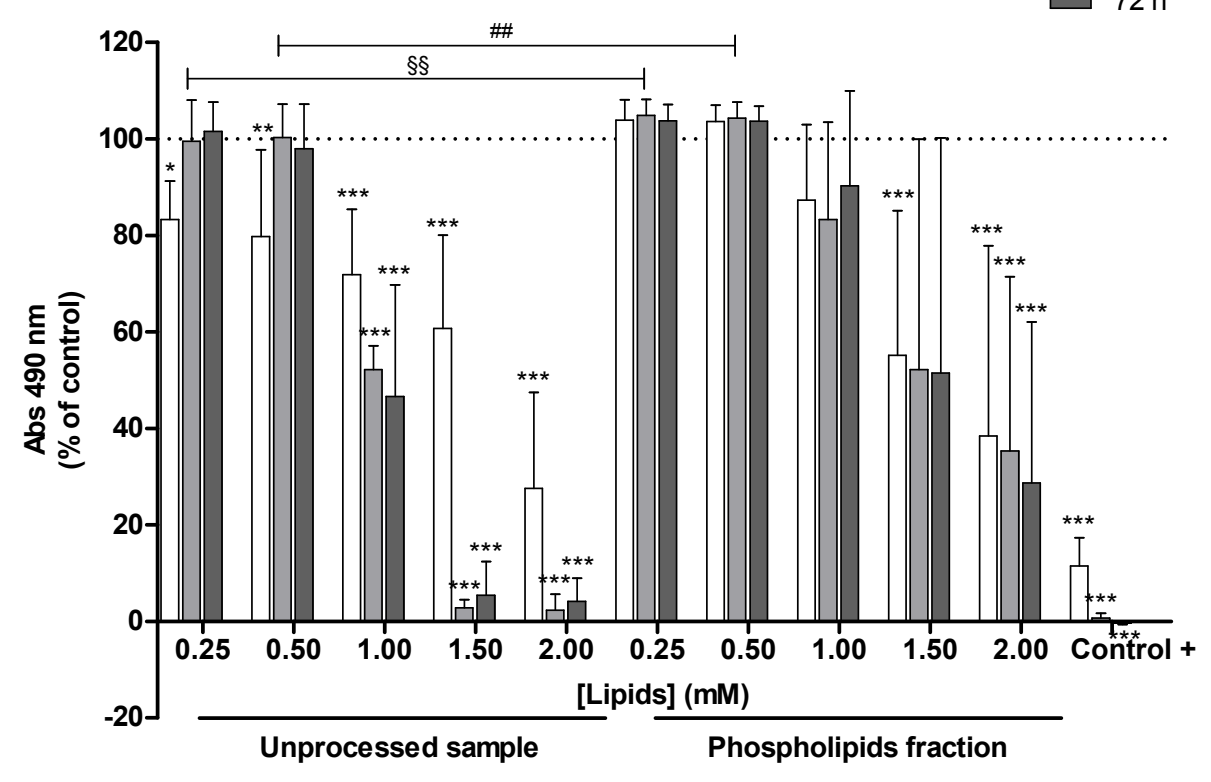

B

Methyl-tert-butyl ether

Time (h)

एखा $24 \mathrm{~h}$

एाIA $48 \mathrm{~h}$

$72 \mathrm{~h}$

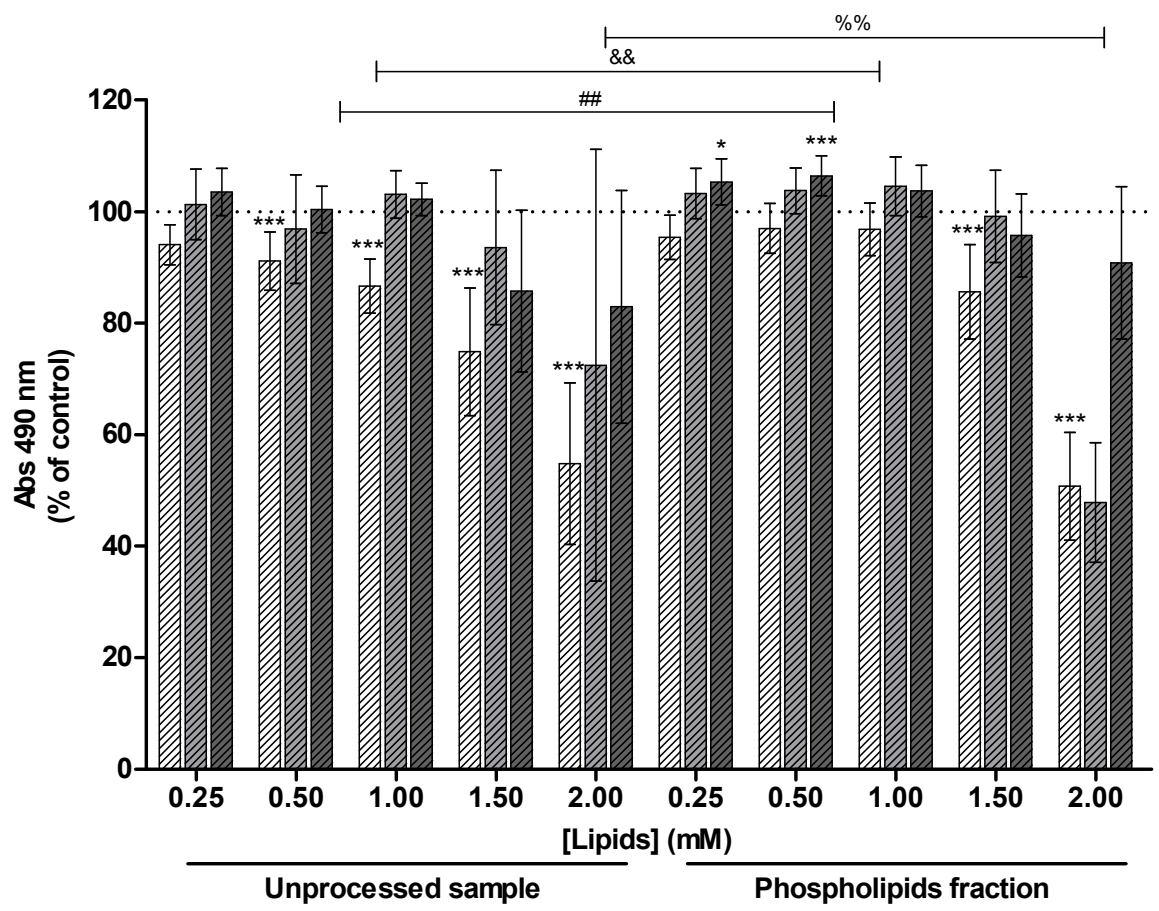


Figure 5 - Effect of MLVs on L929 cells metabolic activity. Cells were or not (control; dashed line corresponding to $100 \%)$ incubated with different concentrations $(0.25,0.50,1.00,1.50$ and $2.00 \mathrm{mM}$ ) of MLVs obtained from BD (A) or MTBE (B) methods extracts, submitted or not to chemical extraction, for 24,48 and $72 \mathrm{~h}$. Data are shown as arithmetic means \pm SD. * $p<0.05$ versus control; ${ }^{* *} p<0.01$ versus control; ${ }^{* * *} p<0.001$ versus control; $\S \S p<0.01$ versus unprocessed sample at $0.25 \mathrm{mM} ; \# p<0.01$ versus unprocessed sample at $0.50 \mathrm{mM} ; \& \&$ $p<0.01$ versus unprocessed sample at $1.00 \mathrm{mM} ; \% \% p<0.01$ versus unprocessed sample at $2.00 \mathrm{mM}$.

All the tested conditions of liposomes prepared from the lipidic extracts obtained by the BD method had a negative effect on L929 cells proliferation (Figure 6A). The chemical extraction reduced this effect, namely for the concentrations $0.50(24 \mathrm{~h})$ and $1.00 \mathrm{mM}(72 \mathrm{~h})$, for which the difference was statistically significant. Regarding the MLVs obtained by the MTBE method, the highest tested concentrations $(1.00,1.50$ and $2.00 \mathrm{mM})$ presented cytotoxicity, for all time-points. However, the liposomes produced from extracts obtained by the MTBE method had a lower negative effect on cells than those obtained by the BD method. The removal of free fatty acids did not significantly influence the effect of MTBE extraction-derived 
cytotoxic.

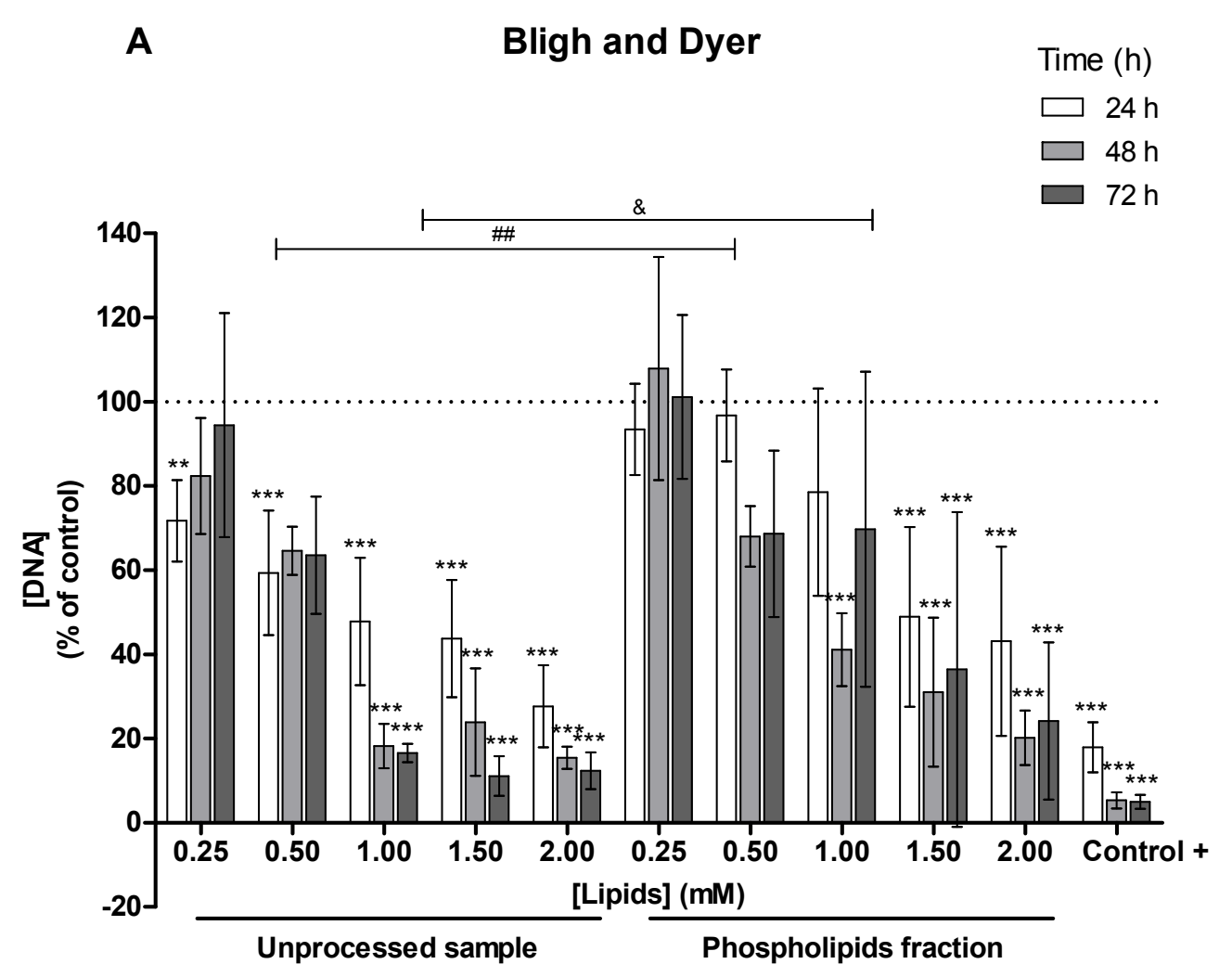




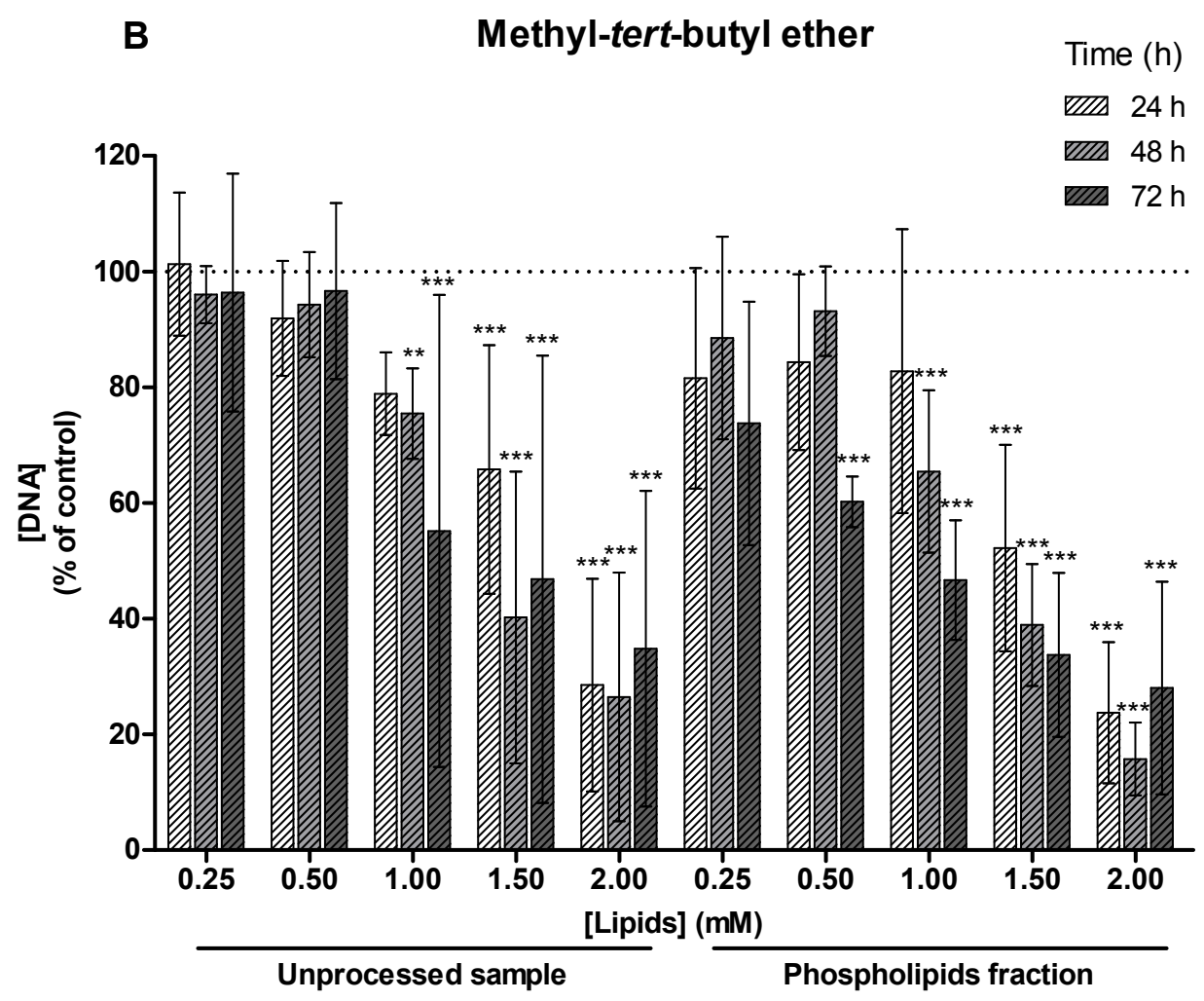

Figure 6 - Effect of MLVs on L929 cells proliferation. Cells were or not (control; dashed line corresponding to $100 \%)$ incubated with different concentrations $(0.25,0.50,1.00,1.50$ and $2.00 \mathrm{mM}$ ) of MLVs obtained from BD (A) or MTBE (B) methods extracts, submitted or not to chemical extraction, for 24,48 and $72 \mathrm{~h}$. Data are shown as arithmetic means \pm SD. ${ }^{* *} p<0.01$ versus control; ${ }^{* * *} p<0.001$ versus control; \#\# $p<0.01$ versus unprocessed sample at 0.50 $\mathrm{mM} ; \& p<0.05$ versus unprocessed sample at $1.00 \mathrm{mM}$.

\section{Total protein quantification}


In terms of protein concentration, the effect of the BD method-derived MLVs followed the same trend observed in cell metabolic activity and proliferation, that is, it was negative for the highest tested concentrations (1.00, 1.50 and $2.00 \mathrm{mM}$ ), for all time-points (Figure 7A). The protein synthesis was improved with the additional step of free fatty acids removal, and the difference was statistically significant for the concentrations $0.50(24 \mathrm{~h}), 1.00$ (24 and $72 \mathrm{~h}$ ) and $2.00 \mathrm{mM}(24 \mathrm{~h})$. As it can be observed in Figure 7B, the MTBE method led to liposomes with a lower negative impact on protein synthesis. The processing of the lipidic extracts did not have a meaningful effect on this parameter of cell performance.

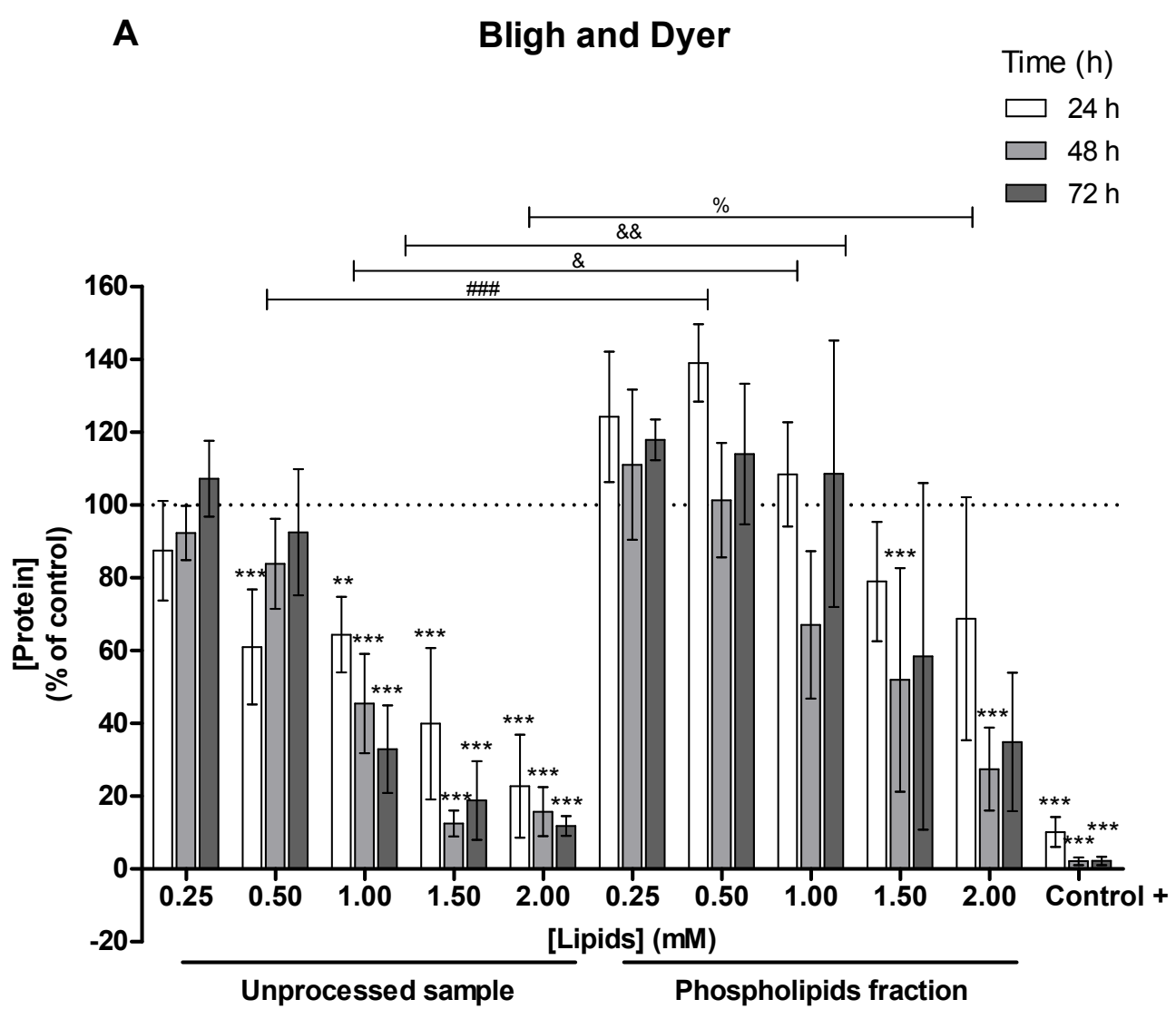




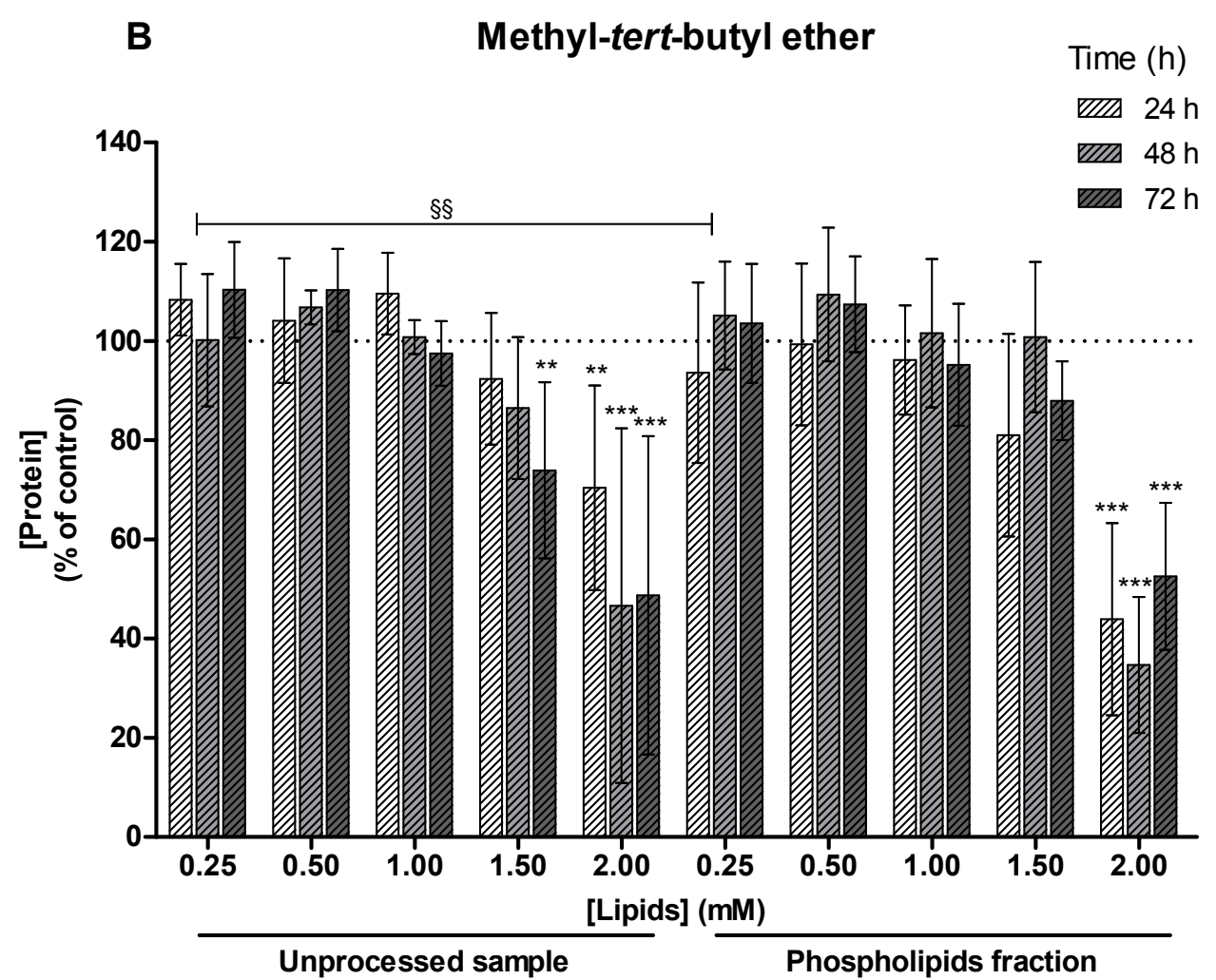

Figure 7 - Effect of MLVs on the total protein content of L929 cells. Cells were or not (control; dashed line corresponding to $100 \%)$ incubated with different concentrations $(0.25,0.50,1.00$, 1.50 and $2.00 \mathrm{mM}$ ) of lipids obtained from BD (A) or MTBE (B) methods extracts, submitted or not to chemical extraction, for 24,48 and $72 \mathrm{~h}$. Data are shown as arithmetic means \pm SD. ** $p<0.01$ versus control; ${ }^{* * *} p<0.001$ versus control; \#\# $p<0.001$ versus unprocessed sample at $0.50 \mathrm{mM} ; \& p<0.05$ versus unprocessed sample at $1.00 \mathrm{mM} ; \& \& p<0.01$ versus unprocessed sample at $1.00 \mathrm{mM} ; \% \mathrm{p}<0.05$ versus unprocessed sample at $2.00 \mathrm{mM}$.

\section{Entrapment efficiency and in vitro release profile of celecoxib}


The entrapment efficiency of the celecoxib in MLVs prepared from unprocessed samples obtained by the MTBE method was $68.5 \pm 17.5 \%$, showing that liposomes present the ability to efficiently encapsulate this NSAID. Indeed, the NSAID concentration into MLVs was of 385 $\pm 145 \mu \mathrm{M}$.

Regarding the celecoxib release profile, it was sustained for seven days (Figure 8). During this period, the drug released from the MLVs was $72.6 \pm 2.2 \%$ (liposomes retained $27.4 \%$ of their initial celecoxib content). This drug was not detected in the release medium by HPLC analyses during the time studied, probably due to its precipitation.

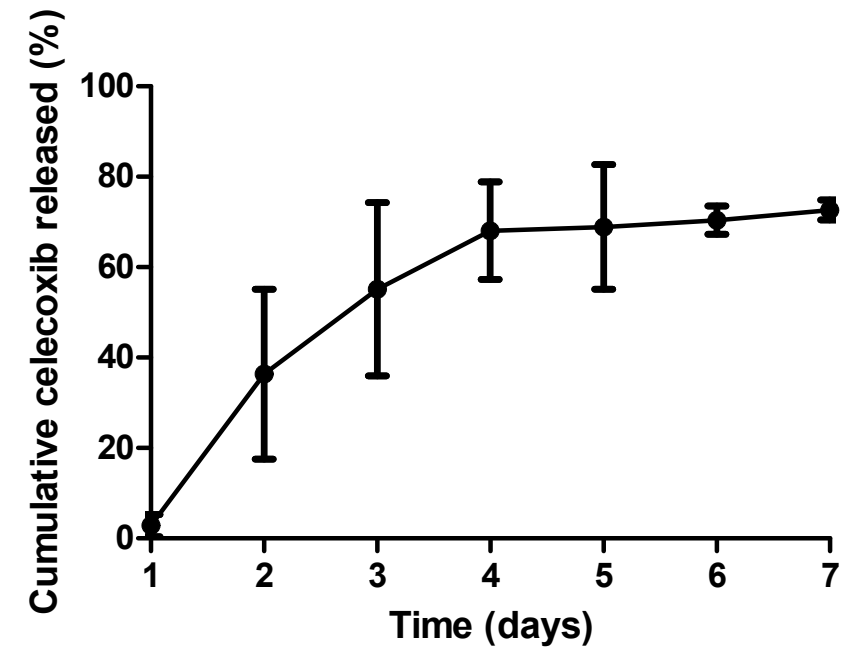

Figure 8 - Celecoxib release profile from MLVs prepared from the unprocessed sample obtained by the MTBE method, incubated in HEPES buffer at $37^{\circ} \mathrm{C}$. Data are shown as arithmetic means \pm SD. 


\section{Discussion}

The main aim of the present work was to extract and identify sardine roe-derived lipids for the preparation of liposomes with enhanced and advantageous properties. The sardine roederived liposomes were characterized, and their cytotoxicity and drug entrapment ability were evaluated to assess their potential to be used as drug delivery systems.

The specie of sardine (Sardina pilchardus) used in this work is a multiple spawning fish, with indeterminate annual fecundity, and in which the spawning batch presents diverse oocytes, in different developmental stages ${ }^{16}$ Roe was obtained from fishes in the spawning capable phase of the reproductive cycle. According to Brown-Peterson and collaborators, ${ }^{38}$ this is the third phase in the reproductive cycle of female fishes (immature, developing, spawning capable, regressing and regenerating phases) and it is characterized by the simultaneous presence of oocytes in any phase of vitellogenesis (CA and vitellogenic oocytes - Vtg1, Vtg2 and Vtg3) and mature oocytes [early germinal vesicle migration (EGVM), late germinal vesicle migration (LGVM), germinal vesicle breakdown (GVBD) and hydration]. Therefore, the sardine roe morphology and histology were assessed to characterize the oocytes and their stages of development (Figure 1 and Figure 2A). Histological analyses were complemented by histochemical staining to evaluate the presence of various classes of 
compounds. During the spawning period, nutritional compounds, such as lipids, proteins, vitamins, and minerals are mobilized to the gonads in order to ensure their maturation ${ }^{40}$ and, consequently, a specific distribution can be observed in the oocytes.

Staining with $A B$ demonstrates the presence of sulfated GAGs (Figure 2B). Sulfated GAGs include chondroitin sulfate, dermatan sulfate, keratan sulfate, heparin, and heparan sulfate, which are present in the cell membranes and in the extracellular matrix. ${ }^{41}$ These complex polysaccharides have important roles in diverse biological functions, such as cell growth, differentiation, morphogenesis, migration and signaling; lipid transport and metabolism; blood coagulation; inflammation; angiogenesis and cancer, through the interaction with various proteins (e.g. growth factors, enzymes, cytokines). ${ }^{41-42}$ Consequently, GAGs can have several applications in the pharmaceutical, nutraceutical, and cosmetic fields. Therefore, sardine roe may be a potential and alternative source of GAGs.

The MT staining performed in the present work did not reveal the presence of collagen fibers (Figure 2C). Although being unexpected, since for instance it is reported that the basement membrane of the oocyte is rich in collagen fibers, ${ }^{43}$ this result can be related to a low expression of collagen by the analyzed samples. Indeed, very low expression of the collagen genes has been already described for zebrafish oocytes. ${ }^{44}$ 
Lipid deposits were observed after Oil Red O staining (Figure 2D). This stain reveals the presence of neutral lipids, such as squalene and other hydrocarbons, mono-, di-, and triglycerides, wax esters, glyceryl ether esters, cholesterol esters, cholesterol or other sterols, free fatty acids, and traces of other neutral lipids (e. g. vitamin A esters). ${ }^{45}$ Neutral lipids function mainly as an energy source, ${ }^{46}$ but also act as a depot of essential structural fatty acids. ${ }^{47}$ Yolk vesicles also stain red in vitellogenic oocytes, which suggest that these cytoplasmic inclusions may have neutral lipids. Indeed, yolk vesicles are not only a source of proteins, but also of phospholipids and some neutral lipids. ${ }^{48}$

Lipid extraction from the sardine roe was further performed in the present work. Since fish eggs lipids are a mixture of nonpolar and polar lipids, the organic solvents should be sufficiently polar to promote high solubility of all classes of lipids. The extraction of all major classes of lipids is traditionally performed using a mixture of chloroform, methanol, and water, as described by $\mathrm{BD}^{28}$ or Folch. ${ }^{30}$ Matyash and co-authors ${ }^{29}$ pioneered a green approach using MTBE for lipids extraction. The advantages of MTBE extraction over conventional methods also include the low density and high hydrophobicity of MTBE. Consequently, the access to the upper lipid-containing organic phase is easier and the contamination by the aqueous phase or by the non-extractable insoluble material (at the interface of 
water/methanol and chloroform phases in the BD extraction method) is minimized. Additionally, when compared with chloroform, MTBE is non-toxic and non-carcinogenic, being an environmentally friendly solvent and reducing the health risk for laboratory personnel. MTBE is also non-corrosive and chemically stable, does not produce peroxides during storage, and presents no risk of modification of labile lipids.

In the present work, BD and MTBE methods were used to extract lipids from sardine roe. Additionally, free fatty acids were removed (and not removed) from the lipid fraction by chemical extraction due to their reported toxic effect on mammalian cells. ${ }^{49}$

To verify if both extraction methods are able to extract a similar lipidic phase, the fatty acid profile was analyzed. The content of fatty acids was similar in both extraction methods (Table 1). However, a higher heterogeneity of fatty acids profile was observed in the extracts obtained using the BD method. Since chloroform/methanol mixture presents a relative higher polarity than MTBE, ${ }^{50}$ it can extract more efficiently lipids with a wide range of polarity. ${ }^{51}$ This

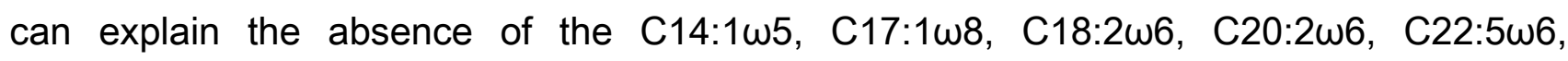
C22:1 $1 \omega 11, \mathrm{C} 22: 5 \omega 3$ fatty acids in the MTBE lipidic extract. Chemical extraction also led to variations in the fatty acid profile. Regarding BD method, only seven fatty acids existing in higher concentration remained after chemical extraction (C14:0, C16:0, C18:0, C16:1w7, 
$\mathrm{C} 18: 1 \Delta 9$ trans, $\mathrm{C} 22: 5 \omega 6, \mathrm{C} 22: 6 \omega 3)$, excepting the $\mathrm{C} 20: 5 \omega 3$ fatty acid (EPA). In relation to the MTBE method, eight fatty acids were obtained after chemical extraction (the same of BD method plus $C 18: 1 \Delta 9$ cis fatty acid). The majority of the absent fatty acids were present in low concentrations in the unprocessed sample and, consequently, this additional step can decrease their concentrations below the detection limit of the quantification method used in this work. Overall, SFA comprised around $60 \%$ of total fatty acids in all samples, while the percentage contribution of MUFA and PUFA was around $27 \%$ and $14 \%$, respectively. These percentages are slightly different from others reported in the literature. ${ }^{19,}{ }^{52}$ However, it is difficult to generalize the fatty acid profile of fish species, since it is profoundly influenced by several factors, such as stage of the reproductive cycle, age, size, diet, environmental temperature, season, and geographical location. ${ }^{40}$

The extraction yield of the MTBE method was higher than the one achieved by the BD method, but in terms of phospholipids and phosphatidylcholine concentrations, both methods are comparable (Table 2). Similar findings have already been reported by other authors. ${ }^{29,} 34$ Considering the disadvantages of using the BD method (mentioned above), the MTBE method is highly preferred as an alternative green approach. As phosphatidylcholine is the predominant phospholipid in fish eggs, its amount was determined. ${ }^{47}$ Indeed, 
phosphatidylcholine accounted for approximately $76.0 \%$ and $87.6 \%$ of the total phospholipids in the BD and MTBE extracts, respectively. This is in agreement with a study performed by Bandarra and co-authors, ${ }^{53}$ in which they demonstrated that the proportion of phosphatidylcholine in sardine in the fatty season was $85.09 \%(\mathrm{w} / \mathrm{w})$.

Envisioning a pharmaceutical application of the extracted lipids, the main objective was to produce drug delivery systems, namely sardine roe-derived liposomes. The produced MLVs presented considerable heterogeneity in terms of size, a significant negative surface charge and a spherical shape (Table 3 and Figure 3). On the one hand, as further processing (e.g. extrusion) was not performed after the dispersion of phospholipids into water, a polydisperse population of liposomes in terms of size was expected. On the other hand, the negative zeta potential of MLVs is most likely related to the presence of anionic phospholipids, such as phosphatidylethanolamine (one of the most abundant phospholipids in teleost fishes). ${ }^{47} \mathrm{~A}$ pronounced non-neutral zeta-potential value is advantageous since the charged particles will tend to repel each other reducing the aggregation and thus increasing the suspension stability.

One of the main physical characteristics of the lipid bilayers is the existence of a temperature - phase transition temperature - that defines two thermodynamically distinct phases: at a 
temperature below the phase transition temperature, liposomes are in the gel phase (associated to a low fluidity), whereas at a temperature above, the lipid bilayer is in the fluid phase (characterized by high fluidity). The phase transition temperature is specific for each lipid and, consequently, membranes with a homogeneous composition (e.g. DPPC liposomes) ${ }^{54}$ have a single phase transition temperature, whereas mixtures of natural phospholipids, presenting different fatty acids (e.g. egg yolk phosphatidylcholine - EPC), will exhibit a complex thermal behavior. ${ }^{55}$ The phase transition temperature of each phospholipid depends on their acyl chain length, degree of unsaturation, and geometry and location of the double bounds along the chain. ${ }^{56}$ In the present work, despite phosphatidylcholine was the predominant phospholipid (Table 2), the fatty acid composition was more complex (Table 1), and the different mixtures presented three endothermic peaks at approximately similar temperatures (Figure 4).

The effect of the MLVs obtained by both extraction methods on cell metabolic activity, proliferation, and total protein content was concentration-dependent (Figures 5, 6 and 7). A superior cytocompatibility was obtained after chemical extraction, particularly for the extracts obtained by the BD method. Additionally, the cytocompatibility was higher for MLVs produced using phospholipids obtained by the MTBE method than by the BD method. MLVs have been 
studied regarding the cytocompatibility of the carrier per se. For instance, Ferreira and coauthors demonstrated that MLVs composed up to $750 \mu \mathrm{M}$ of EPC did not induce toxicity for human fibroblasts. ${ }^{57}$ In addition, MLVs formed from salmon lecithin did not show any effect on neuronal metabolic activity. ${ }^{58}$

The evaluation of the entrapment efficiency and the in vitro release profile of celecoxib indicated that sardine roe-derived MLVs can be used as drug carriers. An entrapment efficiency of $68.5 \%$ was obtained. Some studies have shown similar results for this NSAID, despite different formulations were used. Deniz and co-authors, for example, prepared different liposomal formulations with 1,2-Distearoyl-sn-glycero-3-phosphocholine (DSPC) and cholesterol, and the entrapment efficiency of celecoxib in these MLVs were from 82.4 to $112.0 \%$. ${ }^{59}$ Other celecoxib loaded liposomes, consisting of soya lecithin and cholesterol, had an entrapment efficiency of $67.3 \%{ }^{60}$ The entrapment efficiency of this NSAID in liposomes prepared by Guo et al. was $98.4 \% .{ }^{61}$ In addition to the entrapment efficiency, the effective concentration of the drug into the liposomes is an important parameter to be considered. ${ }^{62}$ In fact, the entrapment efficiency per se can lead to misleading interpretations, because it is based on a ratio of concentrations (the concentration of the drug effectively entrapped and the concentration initially used). Considering the reported clinically relevant 
concentrations of celecoxib in the synovial fluid and plasma $(0.3-10 \mu \mathrm{M}),{ }^{63-64}$ the concentration of this NSAID entrapped into MLVs $(385 \pm 145 \mu \mathrm{M})$ is able to counteract an inflammatory scenario.

The MLVs prepared from unprocessed samples and obtained by the MTBE method were able to sustain the release of celecoxib over seven days. After this period of time, $73 \%$ of the initial drug content was released. The determination of the celecoxib concentration released from liposomes was performed using the drug-loaded liposomes or the release medium. This antiinflammatory drug was detected in the MLVs, but it was difficult to find in the medium due to its low solubility in aqueous solutions. Indeed, as celecoxib is hydrophobic, it is located in the lipid bilayer, interacting with the nonpolar chains of the phospholipids. ${ }^{65}$ It has been reported that MLVs can be readily phagocytized by macrophages. ${ }^{66}$ Therefore, a controlled delivery of celecoxib into the desired cells (i.e. macrophages) can be obtained. The described features of the developed liposomes are essential to improve efficacy and to reduce the dosage concentration as well as the side effects of the encapsulated drug. Moreover, the composition of the developed MLVs presents an added value in the development of drug delivery systems. Indeed, the high level of $\omega 3$ PUFA and other important lipids and fat-soluble compounds, such as a-tocopherol, ${ }^{67}$ is certainly advantageous. w3 PUFA has a wide range of positive 
effects, including anti-inflammatory properties ${ }^{68}$ and the antioxidants (e.g. $\alpha$-tocopherol) will neutralize radical species that are upregulated in inflammation, and can also protect liposomes against oxidation. ${ }^{69}$ Therefore, considering the abovementioned constitution of the developed MLVs, a synergistic action with the entrapped drugs can be obtained. To the best of our knowledge, the present work is the first reporting the use of sardine roe-derived phospholipids to produce liposomes as drug delivery systems. 


\section{Conclusions}

Sardine (Sardina pilchardus) roe was used in the present work to extract and identify relevant compounds, namely lipids, which were used to produce liposomes. Regarding the morphological and histological results, sardines were in the spawning capable phase of the reproductive cycle, which led to the observation of oocytes in different stages. Lipids and phospholipids were successfully extracted from sardine roe, using BD and MTBE methods. The MTBE method presented a higher extraction yield compared with the BD method. Moreover, biological assays indicated that the effect of MLVs on L929 cells metabolic activity, proliferation, and protein content was both concentration and extraction method-dependent. MLVs obtained using MTBE method-derived lipidic extracts presented a higher cytocompatibility than MLVs obtained by the BD method. However, a superior cytocompatibility was obtained after the chemical extraction of the extracts, particularly for the BD method. Therefore, the BD method as the traditional method for the extraction of lipids from marine resources can be efficiently replaced by the MTBE method, which is more environmentally friendly. The developed MLVs presented the ability to encapsulate relevant amounts and to control the release of the anti-inflammatory celecoxib. Moreover, due to MLVs specific composition, synergistic effects with the entrapped drugs are expected.

The developed sardine roe-derived liposomes have therefore a great potential to be used as drug delivery systems. 


\section{Acknowledgements}

Authors acknowledge the financial support from FCT/MCTES and the FSE/POCH, PD/169/2013, for the $\mathrm{PhD}$ grant (PD/BD/113795/2015) attributed to Marta Guedes and the Post-doc Grant attributed to Ana R. Costa-Pinto (SFRH/BPD/90332/2012), and the SPARTAN project (PTDC/CTM$\mathrm{BIO} / 4388 / 2014)$. Authors thank the local fisherman for the donation of the samples, Narcisa Bandarra and Cristina Nunes for their support in the histological analysis, and the staff from the Centre of Biological Engineering of the University of Minho for their collaboration in the fatty acids analysis. 


\section{References}

1. Uddin, M. S.; Kishimura, H.; Chun, B. S., Isolation and characterization of lecithin from squid (Todarodes pacificus) viscera deoiled by supercritical carbon dioxide extraction. Journal of food science 2011, 76 (2), C350-4. DOI: 10.1111/j.1750-3841.2010.02039.x.

2. Dostert, G.; Kahn, C. J. F.; Menu, P.; Mesure, B.; Cleymand, F.; Linder, M.; Velot, É.; Arab-Tehrany, E., Nanoliposomes of Marine Lecithin, a New Way to Deliver TGF- $\beta 1$. J Biomater Tissue Eng 2017, 7(11), 1163-1170. DOI: 10.1166/jbt.2017.1670.

3. Carvalho, C. R.; Lopez-Cebral, R.; Silva-Correia, J.; Silva, J. M.; Mano, J. F.; Silva, T. H.; Freier, T.; Reis, R. L.; Oliveira, J. M., Investigation of cell adhesion in chitosan membranes for peripheral nerve regeneration. Materials science \& engineering. C, Materials for biological applications 2017, 71, 1122-1134. DOI: 10.1016/j.msec.2016.11.100.

4. Hoyer, B.; Bernhardt, A.; Heinemann, S.; Stachel, I.; Meyer, M.; Gelinsky, M., Biomimetically mineralized salmon collagen scaffolds for application in bone tissue engineering. Biomacromolecules 2012, 13 (4), 1059-66. DOI: 10.1021/bm201776r.

5. Reys, L. L.; Silva, S. S.; da Costa, D. S.; Oliveira, N. M.; Mano, J. F.; Silva, T. H.; Reis, R. L., Fucoidan-based Particles for Diabetes Mellitus Treatment. In Tissue Eng Part A, 2015;

Vol. 21, pp S204-S204. 
6. Bledsoe, G. E.; Bledsoe, C. D.; Rasco, B., Caviars and fish roe products. Critical reviews in food science and nutrition 2003, 43 (3), 317-56. DOI: 10.1080/10408690390826545.

7. Kalogeropoulos, N.; Mikellidi, A.; Nomikos, T.; Chiou, A., Screening of macro- and bioactive microconstituents of commercial finfish and sea urchin eggs. Lwt-Food Sci Technol 2012, 46 (2), 525-531. DOI: 10.1016/j.Iwt.2011.11.014.

8. Shirai, N.; Higuchi, T.; Suzuki, H., Effect of lipids extracted from a salted herring roe food product on maze-behavior in mice. J Nutr Sci Vitaminol 2006, 52 (6), 451-6. DOI: 10.3177/jnsv.52.451.

9. Shirai, N.; Higuchi, T.; Suzuki, H., Analysis of lipid classes and the fatty acid composition of the salted fish roe food products, Ikura, Tarako, Tobiko and Kazunoko. Food Chem. 2006, 94 (1), 61-67. DOI: 10.1016/j.foodchem.2004.10.050.

10. Rosa, A.; Scano, P.; Atzeri, A.; Deiana, M.; Falchi, A. M., Potential anti-tumor effects of Mugil cephalus processed roe extracts on colon cancer cells. Food and chemical toxicology : an international journal published for the British Industrial Biological Research Association 2013, 60, 471-8. DOI: 10.1016/j.fct.2013.08.009. 
11. Hayashi, H.; Tanaka, Y.; Hibino, H.; Umeda, Y.; Kawamitsu, H.; Fujimoto, H.; Amakawa, T., Beneficial effect of salmon roe phosphatidylcholine in chronic liver disease. Current medical research and opinion 1999, 15 (3), 177-84. DOI: 10.1185/03007999909114089.

12. Chalamaiah, M.; Jyothirmayi, T.; Diwan, P. V.; Dinesh Kumar, B., Antioxidant activity and functional properties of enzymatic protein hydrolysates from common carp (Cyprinus carpio) roe (egg). Journal of food science and technology 2015, 52 (9), 5817-25. DOI: 10.1007/s13197-015-1714-6.

13. Saravanan, P.; Davidson, N. C.; Schmidt, E. B.; Calder, P. C., Cardiovascular effects of marine omega-3 fatty acids. Lancet (London, England) 2010, 376 (9740), 540-50. DOI: 10.1016/s0140-6736(10)60445-x.

14. Shahidi, F., Omega-3 fatty acids and marine oils in cardiovascular and general health: A critical overview of controversies and realities. J. Funct. Food. 2015, 19, 797-800. DOI: 10.1016/j.jff.2015.09.038.

15. Dal Bello, F.; Santoro, V.; Aigotti, R.; Medana, C.; Gastaldi, D.; Baiocchi, C., Caviar versus brill eggs: A novel high performance liquid chromatography-mass spectrometry 
application for evaluating cosmetic ingredients composition. Eur. J. Lipid Sci. Technol. 2017, 119 (2), 7. DOI: 10.1002/ejlt.201500471.

16. Ganias, K.; Somarakis, S.; Machias, A.; Theodorou, A., Pattern of oocyte development and batch fecundity in the Mediterranean sardine. Fish Res 2004, 67 (1), 13-23. DOI: 10.1016/j.fishres.2003.08.008.

17. Silva, A.; Moreno, A.; Riveiro, I.; Santos, B.; Pita, C.; Garcia Rodrigues, J.; Villasante, S.; Pawlowski, L.; Duhamel, E. Research for Pech Committee - Sardine fisheries: Resource Assessment and Social and Economic situation; 2015. DOI: 10.2861/380993

18. Kechaou, E. S.; Dumay, J.; Donnay-Moreno, C.; Jaouen, P.; Gouygou, J.-P.; Bergé, J.-P.; Amar, R. B., Enzymatic hydrolysis of cuttlefish (Sepia officinalis) and sardine (Sardina pilchardus) viscera using commercial proteases: Effects on lipid distribution and amino acid composition. J Biosci Bioeng 2009, 107 (2), 158-164. DOI: 10.1016/j.jbiosc.2008.10.018.

19. Caponio, F.; Lestingi, A.; Summo, C.; Bilancia, M. T.; Laudadio, V., Chemical characteristics and lipid fraction quality of sardines (Sardina pilchardus W.): influence of sex and length. J. Appl. Ichthyol. 2004, 20(6), 530-535. DOI: 10.1111/j.1439-0426.2004.00611.x. 
20. Gil, A.; Serra-Majem, L.; Calder, P. C.; Uauy, R., Systematic reviews of the role of omega-3 fatty acids in the prevention and treatment of disease. The British journal of nutrition 2012, 107 Supp/ 2, S1-2. DOI: 10.1017/s0007114512001420.

21. Bozzuto, G.; Molinari, A., Liposomes as nanomedical devices. International journal of nanomedicine 2015, 10, 975-99. DOI: 10.2147/ijn.s68861.

22. Monteiro, N.; Martins, A.; Reis, R. L.; Neves, N. M., Liposomes in tissue engineering and regenerative medicine. Journal of the Royal Society, Interface 2014, 11(101), 20140459.

DOI: 10.1098/rsif.2014.0459.

23. Silva, R.; Ferreira, H.; Cavaco-Paulo, A., Sonoproduction of liposomes and protein particles as templates for delivery purposes. Biomacromolecules 2011, 12 (10), 3353-68.

DOI: 10.1021/bm200658b.

24. Dawidczyk, C. M.; Kim, C.; Park, J. H.; Russell, L. M.; Lee, K. H.; Pomper, M. G.; Searson, P. C., State-of-the-art in design rules for drug delivery platforms: lessons learned from FDA-approved nanomedicines. Journal of controlled release : official journal of the Controlled Release Society 2014, 187, 133-44. DOI: 10.1016/j.jconrel.2014.05.036. 
25. Lu, F. S.; Nielsen, N. S.; Timm-Heinrich, M.; Jacobsen, C., Oxidative stability of marine phospholipids in the liposomal form and their applications. Lipids 2011, 46 (1), 3-23. DOI: 10.1007/s11745-010-3496-y.

26. Sezer, A. D.; Akbuğa, J.; Baș, A. L., In Vitro Evaluation of Enrofloxacin-Loaded MLV Liposomes. Drug Deliv 2007, 14 (1), 47-53. DOI: 10.1080/10717540600640146.

27. Singh, H.; Thompson, A.; Liu, W.; Corredig, M., 11 - Liposomes as food ingredients and nutraceutical delivery systems. In Encapsulation Technologies and Delivery Systems for Food Ingredients and Nutraceuticals, Woodhead Publishing: 2012; pp 287-318. DOI: 10.1533/9780857095909.3.287.

28. Bligh, E. G.; Dyer, W. J., A rapid method of total lipid extraction and purification. Canadian journal of biochemistry and physiology 1959, 37(8), 911-7. DOI: 10.1139/059-099.

29. Matyash, V.; Liebisch, G.; Kurzchalia, T. V.; Shevchenko, A.; Schwudke, D., Lipid extraction by methyl-tert-butyl ether for high-throughput lipidomics. Journal of lipid research 2008, 49 (5), 1137-46. DOI: 10.1194/jlr.D700041-JLR200.

30. Folch, J.; Lees, M.; Sloane Stanley, G. H., A simple method for the isolation and purification of total lipides from animal tissues. The Journal of biological chemistry 1957, 226 (1), 497-509. 
31. ISO, ISO 10993-5:2009 Biological evaluation of medical devices. In Part 5: Tests for in vitro cytotoxicity, 2009.

32. Dong, J.; Jiang, D.; Wang, Z.; Wu, G.; Miao, L.; Huang, L., Intra-articular delivery of liposomal celecoxib-hyaluronate combination for the treatment of osteoarthritis in rabbit model. International journal of pharmaceutics 2013, 441 (1-2), 285-90. DOI: 10.1016/j.jpharm.2012.11.031.

33. Gwo, H. H., Morphology of the fertilizable mature egg in the Acanthopagrus latus, A. schlegeli and Sparus sarba (Teleostei: perciformes: sparidae). Journal of microscopy 2008, 232 (3), 442-52. DOI: 10.1111/j.1365-2818.2008.02139.x.

34. Chen, S.; Hoene, M.; Li, J.; Li, Y.; Zhao, X.; Haring, H. U.; Schleicher, E. D.; Weigert, C.; Xu, G.; Lehmann, R., Simultaneous extraction of metabolome and lipidome with methyl tert-butyl ether from a single small tissue sample for ultra-high performance liquid chromatography/mass spectrometry. Journal of chromatography. A 2013, 1298, 9-16. DOI: 10.1016/j.chroma.2013.05.019.

35. Sertoglu, E.; Kurt, I.; Tapan, S.; Uyanik, M.; Serdar, M. A.; Kayadibi, H.; El-Fawaeir, S., Comparison of plasma and erythrocyte membrane fatty acid compositions in patients with 
end-stage renal disease and type 2 diabetes mellitus. Chemistry and physics of lipids 2014, 178, 11-7. DOI: 10.1016/j.chemphyslip.2013.12.011.

36. Bangham, A. D.; Horne, R. W., Negative staining of phospholipids and their structural modification by surface-active agents as observed in the electron microscope. $J \mathrm{Mol} B i \mathrm{O}$ 1964, 8 (5), 660-IN10. DOI: 10.1016/S0022-2836(64)80115-7.

37. Bartlett, G. R., Phosphorus assay in column chromatography. The Journal of biological chemistry 1959, 234 (3), 466-8.

38. Brown-Peterson, N. J.; Wyanski, D. M.; Saborido-Rey, F.; Macewicz, B. J.; LowerreBarbieri, S. K., A Standardized Terminology for Describing Reproductive Development in Fishes. Mar Coast Fish 2011, 3 (1), 52-70. DOI: 10.1080/19425120.2011.555724.

39. Koç, N. D.; Aytekin, Y.; Yüce, R., Ovary maturation stages and histological investigation of ovary of the Zebrafish (Danio rerio). Braz Arch Biol Techn 2008, 51, 513-522. 40. Pacetti, D.; Balzano, M.; Colella, S.; Santojanni, A.; Frega, N. G., Effect of spawning on furan fatty acid profile of edible muscle and organ tissues from sardine (Sardina pilchardus) and anchovy (Engraulis encrasicolus). Journal of agricultural and food chemistry 2013, 61 (16), 3969-77. DOI: 10.1021/jf400555u. 
41. Yamada, S.; Sugahara, K.; Özbek, S., Evolution of glycosaminoglycans: Comparative biochemical study. Commun Integr Bio/2011, 4 (2), 150-158. DOI: 10.4161/cib.4.2.14547.

42. Zhang, F.; Xie, J.; Linhardt, R. J., Isolation and structural characterization of glycosaminoglycans from heads of red salmon (Oncorhynchus nerka). Jacobs $J$ Biotechnol Bioeng 2014, 1 (1), 002.

43. Cotelli, F.; Andronico, F.; Brivio, M.; Lamia, C. L., Structure and composition of the fish egg chorion (Carassius auratus). J Ultrastruct Mol Struct Res 1988, 99 (1), 70-78. DOI: 10.1016/0889-1605(88)90034-1.

44. Gistelinck, C.; Gioia, R.; Gagliardi, A.; Tonelli, F.; Marchese, L.; Bianchi, L.; Landi, C.; Bini, L.; Huysseune, A.; Witten, P. E.; Staes, A.; Gevaert, K.; De Rocker, N.; Menten, B.; Malfait, F.; Leikin, S.; Carra, S.; Tenni, R.; Rossi, A.; De Paepe, A.; Coucke, P.; Willaert, A.; Forlino, A., Zebrafish Collagen Type I: Molecular and Biochemical Characterization of the Major Structural Protein in Bone and Skin. Sci Rep 2016, 6, 21540. DOI: 10.1038/srep21540.

45. Horning, M. G., Chapter 1 - Methods for the Study of Lipid Changes in Biological Experiments. In Medicinal Chemistry, Paoletti, R., Ed. Elsevier: 1964; Vol. 2, pp 1-62. DOI: 10.1016/B978-0-12-544952-6.50006-X. 
46. Suloma, A.; Ogata, H. Y., Lipid and Fatty Acid Composition of Commercially Important Tropical Freshwater Fish Gonads: Guidelines for Specific Broodstock Diet. Turk J Fish Aquat Sc 2012, 12 (4), 743-749. DOI: 10.4194/1303-2712-v12_4_02.

47. Wiegand, M. D., Composition, accumulation and utilization of yolk lipids in teleost fish. Rev. Fish. Biol. Fish. 1996, 6 (3), 259-286. DOI: 10.1007/bf00122583.

48. Johnson, R. B., Lipid Deposition in Oocytes of Teleost Fish During Secondary Oocyte Growth. Rev Fish Sci 2009, 17(1), 78-89. DOI: 10.1080/10641260802590004.

49. Kigoshi, S.; Ito, R., High levels of free fatty acids in lymphoid cells, with special reference to their cytotoxicity. Experientia 1973, 29 (11), 1408-1410. DOI: 10.1007/bf01922845.

50. Reichardt, C., Solvents and Solvent Effects in Organic Chemistry. 3rd ed.; Germany, 2003.

51. Löfgren, L.; Forsberg, G.-B.; StåhIman, M., The BUME method: a new rapid and simple chloroform-free method for total lipid extraction of animal tissue. Sci Rep 2016, 6, 27688. DOI: $10.1038 / \mathrm{srep} 27688$.

52. Garrido, S.; Rosa, R.; Ben-Hamadou, R.; Cunha, M. E.; Chicharo, M. A.; van der Lingen, C. D., Effect of maternal fat reserves on the fatty acid composition of sardine (Sardina 
pilchardus) oocytes. Comparative biochemistry and physiology. Part B, Biochemistry \& molecular biology 2007, 148 (4), 398-409. DOI: 10.1016/j.cbpb.2007.07.008.

53. Bandarra, N. M.; Batista, I.; Nunes, M. L.; Emphis, J. M.; Christie, W. W., Seasonal Changes in Lipid Composition of Sardine (Sardina pilchardus). Journal of food science 1997, 62 (1), 40-42. DOI: doi:10.1111/j.1365-2621.1997.tb04364.x.

54. Pentak, D., Alternative methods of determining phase transition temperatures of phospholipids that constitute liposomes on the example of DPPC and DMPC. Thermochim Acta 2014, 584, 36-44. DOI: 10.1016/j.tca.2014.03.020.

55. Li, J.; Wang, X.; Zhang, T.; Wang, C.; Huang, Z.; Luo, X.; Deng, Y., A review on phospholipids and their main applications in drug delivery systems. Asian J Pharm Sci2015, 10 (2), 81-98. DOI: 10.1016/j.ajps.2014.09.004.

56. Biltonen, R. L.; Lichtenberg, D., The use of differential scanning calorimetry as a tool to characterize liposome preparations. Chemistry and physics of lipids 1993, 64 (1), 129-142.

DOI: 10.1016/0009-3084(93)90062-8.

57. Ferreira, H.; Matama, T.; Silva, R.; Silva, C.; Gomes, A. C.; Cavaco-Paulo, A., Functionalization of gauzes with liposomes entrapping an anti-inflammatory drug: A strategy 
to improve wound healing. Reactive \& Functional Polymers 2013, 73 (10), 1328-1334. DOI:

10.1016/j.reactfunctpolym.2013.05.012.

58. Hasan, M.; Latifi, S.; Kahn, C. J. F.; Tamayol, A.; Habibey, R.; Passeri, E.; Linder, M.; Arab-Tehrany, E., The Positive Role of Curcumin-Loaded Salmon Nanoliposomes on the Culture of Primary Cortical Neurons. Marine drugs 2018, 16 (7). DOI: 10.3390/md16070218.

59. Deniz, A.; Sade, A.; Severcan, F.; Keskin, D.; Tezcaner, A.; Banerjee, S., Celecoxibloaded liposomes: effect of cholesterol on encapsulation and in vitro release characteristics. Bioscience Reports 2010, 30 (5), 365-373. DOI: 10.1042/bsr20090104.

60. Moghimipour, E.; Handali, S., Utilization of thin film method for preparation of celecoxib loaded liposomes. Advanced Pharmaceutical Bulletin 2012, 2 (1), 93-98. DOI: 10.5681/apb.2012.013.

61. Guo, J. W.; Guan, P. P.; Ding, W. Y.; Wang, S. L.; Huang, X. S.; Wang, Z. Y.; Wang, P., Erythrocyte membrane-encapsulated celecoxib improves the cognitive decline of Alzheimer's disease by concurrently inducing neurogenesis and reducing apoptosis in APP/PS1 transgenic mice. Biomaterials 2017, 145, 106-127. DOI: 10.1016/j.biomaterials.2017.07.023. 
62. Ferreira, H.; Silva, R.; Matama, T.; Silva, C.; Gomes, A. C.; Cavaco-Paulo, A., A biologically active delivery material with dried-rehydrated vesicles containing the antiinflammatory diclofenac for potential wound healing. Journal of liposome research 2016, 26 (4), 269-75. DOI: 10.3109/08982104.2015.1108333.

63. Page, T. H.; Turner, J. J.; Brown, A. C.; Timms, E. M.; Inglis, J. J.; Brennan, F. M.; Foxwell, B. M.; Ray, K. P.; Feldmann, M., Nonsteroidal anti-inflammatory drugs increase TNF production in rheumatoid synovial membrane cultures and whole blood. Journal of immunology (Baltimore, Md. : 1950) 2010, 185 (6), 3694-701. DOI: 10.4049/jimmunol.1000906.

64. Mastbergen, S. C.; Lafeber, F. P.; Bijlsma, J. W., Selective COX-2 inhibition prevents proinflammatory cytokine-induced cartilage damage. Rheumatology (Oxford, England) 2002, 41 (7), 801-8. DOI: 10.1093/rheumatology/41.7.801.

65. Riahi, M. M.; Sahebkar, A.; Sadri, K.; Nikoofal-Sahlabadi, S.; Jaafari, M. R., Stable and sustained release liposomal formulations of celecoxib: In vitro and in vivo anti-tumor evaluation. International journal of pharmaceutics 2018, 540 (1-2), 89-97. DOI: 10.1016/j.ijpharm.2018.01.039. 
66. Katragadda, A.; Bridgman, R.; Betageri, G., Effect of liposome composition and cholesterol on the cellular uptake of stavudine by human monocyte/macrophages. Cell. Mol. Biol. Lett. 2000, 5(4), 483-493.

67. Passi, S.; Cataudella, S. F.; Di Marco, P.; De Simone, F.; Rastrelli, L., Fatty acid composition and antioxidant levels in muscle tissue of different Mediterranean marine species of fish and shellfish. Journal of agricultural and food chemistry 2002, 50 (25), 7314-7322. DOI: $10.1021 / \mathrm{jfO} 20451 \mathrm{y}$.

68. Carlson, S. J.; Fallon, E. M.; Kalish, B. T.; Gura, K. M.; Puder, M., The role of the omega-3 fatty acid DHA in the human life cycle. JPEN. Journal of parenteral and enteral nutrition 2013, 37(1), 15-22. DOI: 10.1177/0148607112467821.

69. Ferreira, H.; Gonçalves, V. M. F.; Silva, R.; Tiritan, M. E.; Teixeira, M.; Cavaco-Paulo, A., Development of Liposomes-in-Hydrogel Formulations Containing Betamethasone for Topical Therapy. J Pharmaceut Drug Deliv Safety 2017 1(1). 


\section{For Table of Contents Use Only}

\section{Sardine roe as a source of lipids to produce liposomes}

Marta Guedes, Ana R. Costa-Pinto, Virgínia M. F. Gonçalves, Joana Moreira-Silva, Maria Elizabeth Tiritan, Rui. L. Reis, Helena Ferreira, Nuno M. Neves

Table of Contents graphic

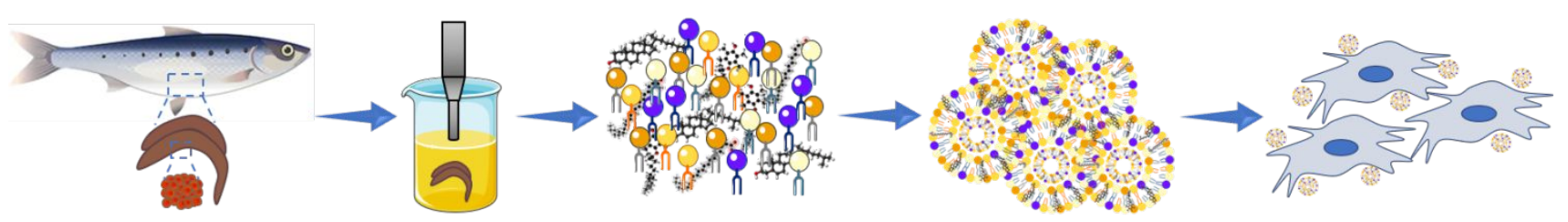

